\title{
ESTILOS DE APRENDIZAJE Y CURRÍCULUM: PROPUESTAS DE MEJORA \\ FACULTAD DE MEDICINA DE ZARAGOZA
}

Jesús Fernando Escanero Marcén (Director)

\section{pers}

Prensas Universitarias de Zaragoza 

ESTILOS DE APRENDIZAJE Y CURRÍCULUM:

PROPUESTAS DE MEJORA

FACULTAD DE MEDICINA DE ZARAGOZA 


\section{Director}

Escanero MarcÉn, Jesús Fernando

Catedrático de Fisiología, Facultad de Medicina,

Universidad de Zaragoza (España)

\section{Coordinador}

Mora GutiéRREZ, Sergio

Profesor de Farmacología Molecular y Clínica, Facultad de Medicina, Universidad de Chile (Chile)

\section{Autores}

ARCE ARANCIBIA, José

Profesor de Ginecología, Decano de la Facultad de Medicina, Universidad Mayor, Real y Pontificia de San Francisco Xavier de Chuquisaca, Sucre (Bolivia)

BIANCHI, Antonio Ricardo

Profesor Asociado del Área Bioquímica, Facultad de Ciencias Médicas, Universidad Nacional de Cuyo, Mendoza (Argentina)

\section{DíAz-Veliz, Gabriela}

Profesor Asociado del Programa Farmacología Molecular y Clínica, Facultad de Medicina, Universidad de Chile (Chile)

\section{GARgiUlo, Pascual Ángel}

Director del Laboratorio de Neurociencias y Psicología Experimental.

Instituto de Medicina y Biología Experimental de Cuyo (IMBECU).

Consejo Nacional de Investigaciones Científicas y Técnicas (CONICET).

Profesor de Farmacología, Facultad de Ciencias Médicas,

Universidad Nacional de Cuyo, Mendoza (Argentina)

GonZÁlez HARO, Carlos

Profesor Asociado de la Facultad de las Ciencias de la Salud y el Deporte. Huesca (España)

Gorena, Dorian

Profesor de Salud Pública, Director del Área de Salud, Universidad Andina Simón Bolívar, Sucre (Bolivia)

LAFUENTE SÁNCHEZ, José Vicente

Catedrático de Anatomía, Facultad de Medicina, Universidad del País Vasco (España)

Terán CALderón, Carolina

Profesor de Salud Pública, Facultad de Medicina, Universidad Mayor, Real y Pontificia de San Francisco Xavier de Chuquisaca, Sucre (Bolivia) 


\title{
ESTILOS DE APRENDIZAJE Y CURRÍCULUM: PROPUESTAS DE MEJORA
}

FACULTAD DE MEDICINA DE ZARAGOZA

\author{
Jesús Fernando Escanero Marcén
}

(Director) 
ESTILOS de aprendizaje y currículum: propuestas de mejora : Facultad de Medicina de Zaragoza / Jesús Fernando Escanero Marcén (director). — Zaragoza :

Prensas Universitarias de Zaragoza, 2009

104 p. ; $22 \mathrm{~cm}$

ISBN 978-84-92774-30-2

1. Medicina-Didáctica. 2. Estilos de aprendizaje

ESCANERO MARCÉN, Jesús Fernando

$61: 37.025$

Cualquier forma de reproducción, distribución, comunicación pública o transformación de esta obra solo puede ser realizada con la autorización de sus titulares, salvo excepción prevista por la ley. Diríjase a CEDRO (Centro Español de Derechos Reprográficos, www.cedro.org) si necesita fotocopiar o escanear algún fragmento de esta obra.

(C) Los autores

(C) De la presente edición, Prensas Universitarias de Zaragoza

1. ${ }^{\text {a }}$ edición, 2009

Prensas Universitarias de Zaragoza. Edificio de Ciencias Geológicas, c/ Pedro Cerbuna, 12. 50009 Zaragoza, España. Tel.: 976761 330. Fax: 976761063

puz@unizar.es http://puz.unizar.es

Prensas Universitarias de Zaragoza es la editorial de la Universidad de Zaragoza, que edita e imprime libros desde su fundación en 1542.

Diseño de cubierta: David Guirao

Impreso en España

Imprime: Servicio de Publicaciones, Universidad de Zaragoza

D.L.: Z-3332-2009 


\section{ÍNDICE}

\section{CAPÍTULO I}

EL CURRÍCULUM DE MEDICINA EN EL ESPACIO EUROPEO DE EDUCACIÓN SUPERIOR

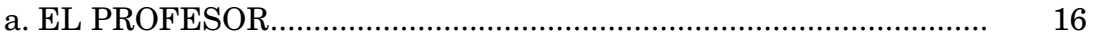

Reflexión y debate ............................................................................ 16

La competencia........................................................................ 16

Las nuevas tecnologías y metodologías. ............................................. 18

La Universidad de Birmingham ............................................. 18

El departamento............................................................................ 20

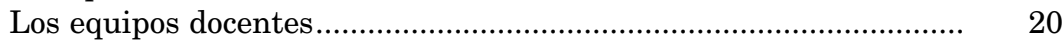

El conocimiento .................................................................................. 22

Tipologías del conocimiento y oportunidades de aprendizaje ...... $\quad 23$

Calidad de los procesos de enseñanza........................................ $\quad 25$

Adquisición del conocimiento y evaluación (control) del mismo. $\quad 26$

b. EL PERSONAL DE ADMINISTRACIÓN Y SERVICIOS ................ 26

c. LAS INFRAESTRUCTURAS …....................................................... 27

Bibliografía ................................................................................. 27

\section{CAPÍTULO II}

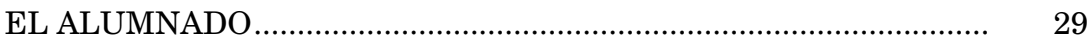

La primera comunicación ............................................................... $\quad 30$

La primera fotofija ....................................................................... 31

Bibliografía .......................................................................................

LOS ANÁLISIS ACTUALES .............................................................

Antecedentes sobre estilos............................................................. 36

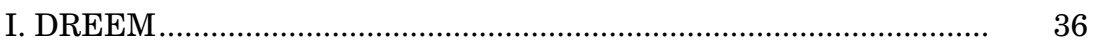

Introducción ....................................................................................... 36

a) El ambiente educacional y herramientas para su exploración.. $\quad 36$

b) Concepto y papel en la educación médica ................................... 38 
Material y métodos ............................................................................. 39

a) Los dos centros de la Universidad de Zaragoza.................... 39

b) Muestra de estudio ................................................................... 40

c) Herramienta utilizada............................................................. $\quad 40$

d) Estadística ............................................................................. 41

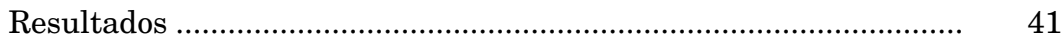

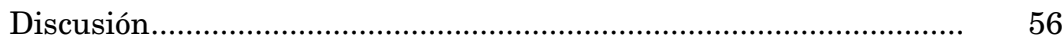

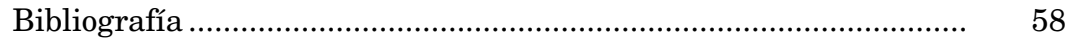

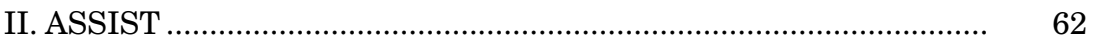

Los enfoques de aprendizaje............................................................. 62

Del ASI (Approaches to Studying Inventory) al ASSIST .................. 64

Material y métodos ........................................................................ 65

a) Muestra de estudio .................................................................. 65

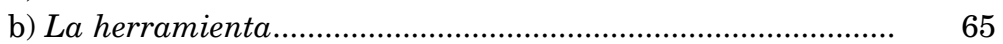

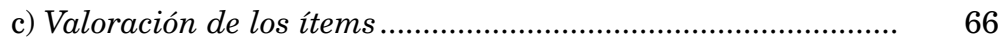

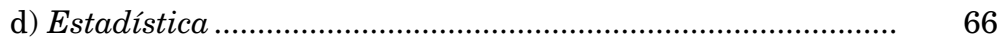

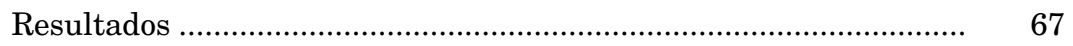

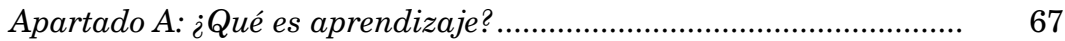

Apartado B: Aproximaciones al estudio ............................................. 67

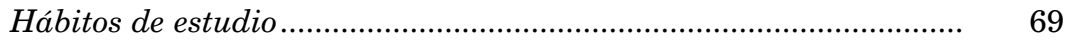

Apartado C: Preferencias por diferentes tipos de curso y enseñanza.. $\quad 69$

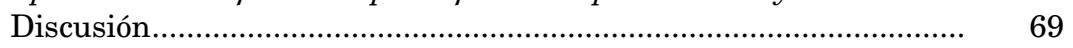

Bibliografía .....................................................................................

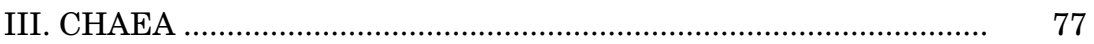

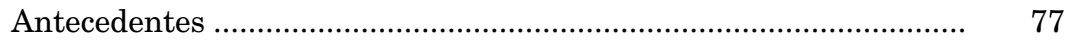

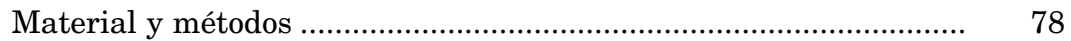

a) Muestra de estudio ...............................................................

b) Instrumento utilizado............................................................. $\quad 78$

c) Conversión al Modelo de Kolb................................................. 78

d) Tratamiento estadístico.......................................................... $\quad 79$

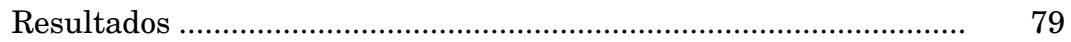

Discusión....................................................................................... 80

Bibliografía .................................................................................. 83

\section{CANFIELD}

Material y métodos ….................................................................... 85

a) Muestra de estudio ...............................................................

b) Herramienta ........................................................................ 85

1) Categorías y dominios de aprendizaje .................................

2) Tipología de aprendedor ................................................... 


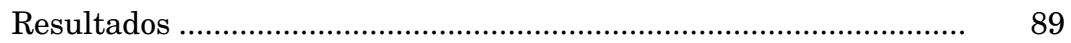

a) Categorías y dominios de aprendizaje .................................. $\quad 89$

b) Tipología de Aprendedor ......................................................... $\quad 89$

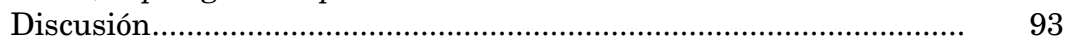

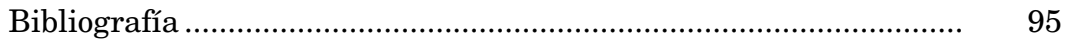

\section{CAPÍTULO III}

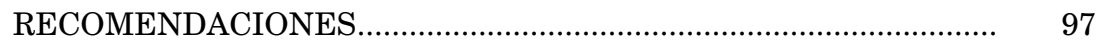

LA REALIDAD ACTUAL ................................................................ 97

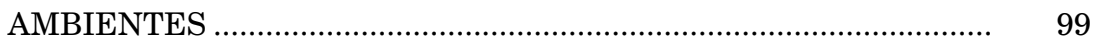

Conclusiones del DREEM ............................................................ 99

ENFOQUE .............................................................................. 102

Conclusiones del ASSIST ............................................................ 102

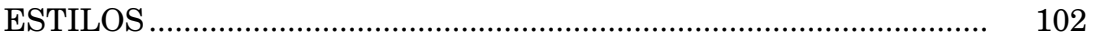

Conclusiones CHAEA ................................................................ 102

PREFERENCIAS Y ESTILOS............................................................ 103

Conclusiones CANFIELD ............................................................ 103 



\section{INDICE DE TABLAS Y FIGURAS}

Tablas

\section{Capítulo I}

Tabla 1. Asignaturas de las diferentes licenciaturas/diplomaturas y centros del departamento de Farmacología y Fisiología.

Tabla 2. Dimensiones, tipos y modalidades de conocimiento

\section{Capítulo II}

Tabla 3. Evaluación global de los procesos psicomatéticos

Tabla 4. Guía para la interpretación de las puntuaciones del DREEM.

Tabla 5. Puntuación de los estudiantes de Medicina (Zaragoza y Huesca) en la percepción del aprendizaje.....

Tabla 6. Puntuación de los estudiantes de Medicina (Zaragoza y Huesca) en la percepción de los profesores (enseñanza).............

Tabla 7. Puntuación de los estudiantes de Medicina (Zaragoza y Huesca) en la auto percepción del ambiente académico

Tabla 8. Puntuación de los estudiantes de Medicina (Zaragoza y Huesca) en la autopercepción del ambiente de aprendizaje.......

Tabla 9. Puntuación de los estudiantes de Medicina (Zaragoza y Huesca) en la autopercepción del ambiente social del estudiante

Tabla 10. Puntuación de los estudiantes de Medicina (Zaragoza y Huesca) en la percepción del ambiente

Tabla 11. Puntuaciones de los alumnos de $1 .^{\circ}, 3 .^{\circ}$ y $5 .^{\circ}$ de la Facultad de Medicina de la Universidad de Zaragoza.....

Tabla 12. Percepciones del medio ambiente de los estudiantes de Zaragoza

Tabla 13. Características asociadas a los enfoques.

Tabla 14. Subescalas que forman cada aproximación

Tabla 15. Preferencia por el tipo de concepto de aprendizaje

Tabla 16. Valores de las aproximaciones al aprendizaje y las respectivas subescalas

Tabla 17. Equivalencia de los estilos de aprendizaje entre CHAEA y Kolb 
Tabla 18. Categorías y dominios de cada una de ellas en el Canfield

Tabla 19. Tipología de aprendedor

86

88

Tabla 20. Estudiantes de Medicina según puntuaciones medias de preferencia en las escalas de categorías del Cuestionario CLSI...

Tabla 21. Distribución de los estudiantes de Medicina según Tipología de Aprendedor.

Tabla 22. Distribución de los estudiantes de Medicina por Tipología de Aprendedor y por curso

90

92

93

Figuras

\section{Capítulo II}

Figura 1. Evaluación global y por escalas.

Figura 2. Puntuaciones totales de los medios ambientes educativos explorados de los alumnos de $1 .^{\circ}, 3 .^{\circ}$ y $5 .^{\circ}$ cursos de las Facultades de Medicina de Zaragoza y Bilbao

Figura 3. Puntuaciones en cada uno de los medios ambientes educativos explorados de los alumnos de $1 .^{\circ}, 3 .^{\circ}$ y $5 .^{\circ}$ cursos de las Facultades de Medicina de Zaragoza y Bilbao

Figura 4. Puntuaciones en cada uno de los medios ambientes educativos explorados de los alumnos de $1 .^{\circ}, 3 .^{\circ}$ y $5 .^{\circ}$ cursos de las Facultades de Medicina de Zaragoza y Bilbao

Figura 5. Estilos de aprendizaje: Puntaje promedio obtenidos para cada estilo de aprendizaje en estudiantes de primer año de las Facultades de Medicina de las universidades indicadas.

Figura 6. Estilos de aprendizaje: Diagrama de dispersión con el estilo preponderante de cada estudiante de primer curso de las Facultades de Medicina de las Universidades del País Vasco (España) y de Zaragoza. Los ejes indican estilos según Kolb/Honey-Alonso. Los porcentajes señalan la proporción de individuos en cada cuadrante (perfil de preferencias individuales). 


\section{AGRADECIMIENTOS*}

Los autores del presente libro quieren hacer explícito su agradecimiento a las siguientes instituciones y personas:

- Agencia Española de Cooperación Internacional (AECI).

- Universidades de Zaragoza y País Vasco (España), Nacional de Cuyo (Mendoza, Argentina), Mayor, Real y Pontificia de San Francisco Xavier y Andina Simón Bolívar (Sucre, Bolivia) y de Chile (Santiago de Chile, Chile).

- Facultades de Medicina de las mencionadas Universidades.

- Instituto de Ciencias de la Educación de la Universidad de Zaragoza.

- Sociedad Española de Educación Médica.

- Decanos de las Facultades de Medicina antes mencionadas.

* Este libro se ha editado con el soporte del proyecto AECI 2008: «Estilos de aprendizaje de los alumnos de Medicina en diferentes contextos curriculares y geográficos. Acciones para la mejora». 



\section{Capítulo I}

\section{EL CURRÍCULUM DE MEDICINA EN EL ESPACIO EUROPEO DE EDUCACIÓN SUPERIOR}

La segunda semana de julio de 2009, el Gobierno Autónomo de Aragón autorizaba la implantación del grado en Medicina en la Facultad de Medicina de Zaragoza a coste cero y demandaba al Rectorado los mecanismos pertinentes para preservar los estudios de Medicina en la Facultad de Ciencias de la Salud y el Deporte de Huesca.

Con esta resolución se daba por supuesto que el profesorado no necesitaba formación, que las infraestructuras estaban en orden, alineadas con el nuevo currículum, que el personal era más que suficiente y que Huesca cuando menos iba a seguir la misma tónica de calidad que la demandada a Zaragoza. En suma, se consumaba una reforma por decreto y se hacía en las fechas debidas, a tres días de las vacaciones estivales.

Y con esto, asumiendo que todo está hecho o cerrando los ojos, la Facultad de Medicina de Zaragoza ya está en Europa.

En este capítulo, siquiera esquemáticamente se van a analizar las deficiencias que se necesitarían corregir en tres puntos clave:
a) Profesorado.
b) Personal de la Administración y Servicios.
c) Infraestructuras. 


\section{a. EL PROFESOR}

\section{Reflexión y debate}

Ni se ha debatido ni reflexionado lo suficiente sobre dos hechos: las posibles lagunas en la preparación del profesorado o, si se prefiere, el nuevo rol del profesor y los diferentes aspectos y matices que la reforma curricular implica. Con motivo de la elaboración de la memoria de Grado y de las primeras Guías Docentes (primer semestre) se iniciaron algunos debates con los profesores: alineamiento constructivo, reducción de clases magistrales a favor de las actividades en pequeños grupos, la evaluación como herramienta de calidad, la utilización del portafolio en la misma, etc. Todo ello, no obstante, quedó a unos niveles que iban poco más allá de los planteamientos.

Este punto es uno de los más álgidos. La Institución, si pretende llevar a cabo la reforma, ni siquiera decimos con éxito o calidad, debe iniciar con urgencia y carácter obligatorio los necesarios debates y procesos de formación entre profesores, con personal externo, $\mathrm{y}$ con una llamada clara a la formación de equipos docentes con una adecuada dinámica de funcionamiento.

Sólo como ejemplo el comentario de más abajo acerca de uno de los temas a tratar: la competencia.

\section{La competencia}

Desde la adhesión de nuestro país al EEES se ha introducido en el sistema universitario un nuevo término: la competencia como base y producto de un determinado tipo de formación (1). Sin embargo, la aplicación de la misma al modelo educativo se ha realizado dando por supuesto que el modelo de Bolonia era relativamente sencillo y adecuado no sólo para ser comprendido por todo el mundo sino para ser llevado a la práctica correctamente. Craso error. Un ejemplo para ponerlo de manifiesto: la mencionada interpretación ha llevado a confundir la competencia con el tiempo destinado a cada materia para cumplir con el programa, lo que supone un ver- 
dadero desastre para la formación del alumno, dicen los profesores. Cuando se mira «hacia atrás», como hace la competencia, el currículum demanda a cada materia lo que necesita para cumplir con el perfil profesional (el producto: outcome learning) que la Sociedad ha diseñado para los profesionales que requiere y no lo que el profesorado de cada materia quiere hacer del futuro médico: un experto al que se le exige más de lo que el profesorado sabe, en muchos casos. Este ejemplo no es más que una expresión del «más de lo mismo».

La ingenuidad de suponer que se trata de un concepto unívoco y que basta con enunciarlo para que se aplique y se obtengan los resultados deseados ha llevado a considerar que la simple inclusión académica bastaría para ser el eje articulador de los nuevos currícula, así como para desarrollar los marcos adecuados, inteligibles y relevantes, de las nuevas propuestas (1). Las competencias deben abordarse desde diferentes materias y las reuniones, los encajes, los planteamientos metodológicos, etc. deben hacerse hasta la saciedad para que cada una de ellas quede lo mejor servida posible dentro del perfil profesional.

A continuación se procede a incluir las causas que han hecho posible esta doble ingenuidad, siguiendo a Rué (1) porque ello podría ser objeto de debate y reflexión para la comunidad del profesorado:

1. El carácter borroso del concepto «competencia».

2. Sus distintas tradiciones de origen y enfoques conceptuales.

3. El papel de las distintas agencias y agentes que intervienen en su definición y especificación y el «ruido» que ello puede introducir.

4. El espacio que hay entre su definición y su desarrollo entre los alumnos.

5. La falta de tradición en la formulación de currícula en Educación Superior en este terreno, lo que incrementa la dificultad de realizar aproximaciones relevantes al mismo.

6. El problema de cómo desarrollar una nueva cultura docente, que refleje un enfoque de la enseñanza-aprendizaje en la Universidad distinto del modelo cultural actualmente hegemónico.

7. Obviar la dificultad de proponer modelos de evaluación suficientemente complejos para las competencias predicadas en una determinada titulación. 
Se trata de una laguna que será preciso ir cubriendo con el desarrollo del nuevo currículum antes de atender propuestas que lleven la balanza hacia el otro platillo. Debe pensarse y tener lo suficientemente asumido que la competencia es la pieza clave que une nuestro quehacer con la demanda de la Sociedad y despegarnos de esta idea es pretender volver al «castillo de cristal» en el que durante mucho tiempo ha habitado nuestra Universidad.

\section{Las nuevas tecnologías y metodologías}

Se ha introducido este tema con objeto de llamar la atención sobre otra necesidad de primer orden: el soporte humano. Aunque el tema se ha iniciado en diferentes ocasiones y se han recomendado metodologías activas, de algunas de las cuales se han impartido seminarios, siempre la respuesta a la petición del apoyo humano queda en la irresolución más completa. El ejemplo siguiente puede servir de guía.

\section{La Universidad de Birmingham}

Se describe en este apartado el papel de las TIC y de sus plataformas como potenciadoras de la autonomía en la enseñanza y el aprendizaje desde un enfoque globalizador e institucional.

La Universidad de Birmingham, como tantas otras del Reino Unido, tiene definida «La visión de Birmingham para el aprendizaje», es decir, la aceptación y asunción, por parte del conjunto de la Universidad, de un compromiso institucional en la promoción de actividades y de situaciones de enseñanza y aprendizaje que asuman determinadas orientaciones de aprendizaje que la Institución ha aceptado.

La siguiente declaración, cuyo enunciado central dice: «En Birmingham nos comprometemos a facilitar a todos nuestros estudiantes el beneficio de una cultura de aprendizaje alineada con nuestro ethos de investigación, el cual se basa en la investigación crítica, en el debate y en la automotivación», enmarca la idea del Aprendizaje Activo de la institución. Algunos de los compromisos que engloba son: 
- Implicarse (los alumnos) en problemas reales, retadores y complejos, que tratan sobre aspectos de la vida real.

- Ir desde el aprendizaje superficial al aprendizaje profundo.

- Reflexionar constructivamente acerca de su propio aprendizaje, mediante el empleo de una variedad de fuentes.

- Compartir el aprendizaje y experiencia con otros, docentes y compañeros.

- Disfrutar del propio aprendizaje procurando que ofrezca recompensas positivas a los estudiantes.

- Etc.

Es en este contexto donde se sitúa el papel de las Tecnologías del Aprendizaje que puedan desarrollarse en la mencionada Universidad (ordenador, paquetes de software, la red -internet-, e-mail, discusión en línea, entornos virtuales, tecnologías de la web 2.0 -You Tube, Flicker, Second Life-, teléfonos móviles, iPods, vídeos, audios, etc.). Y aquí el aspecto que queríamos remarcar: el apoyo a los docentes. Esta acción considera primordial o fundamental proporcionar apoyo a los docentes en el proceso de transformación de su docencia desde el modelo transmisivo al de aprendizaje activo. Son varios los programas o líneas para los que se brinda apoyo (diseño de programas, selección de los enfoques de aprendizaje, diseño de sistemas de evaluación, etc.). También es de remarcar que en algunas facultades (Químicas, Escuela de Empresariales) un miembro del equipo tiene dedicación exclusiva al rol de apoyo al desarrollo de las tecnologías de aprendizaje y el empleo del Entorno Virtual de Aprendizaje (EVAi institucional) para cualquiera de los programas de estudio del centro.

Alumnos de último curso con dedicaciones específicas o personal de la Administración y Servicios especializado o reconvertido podrían cumplir con esta tarea de soporte, sin cuya existencia la reforma se verá muy seriamente afectada. Otra alternativa serían los departamentos de Educación Médica, tema debatido, implementado en otras Facultades de Medicina españolas y suficientemente conocido por la gran mayoría como para pretender introducirlo de nuevo aquí. 


\section{El departamento}

Los departamentos son, en algunos casos, meros lugares de encuentro donde los intereses de un equipo docente pueden ser manejados al capricho de las grandes mayorías o de una minoría del área debido a los intereses y pactos de poder patrocinados por la dimensión multiárea y plurifacultad de los mismos. La reforma y nueva estructuración de los mismos es un capítulo pendiente, cuyo retraso puede lastrar de entrada la marcha de los nuevos curricula (2). Unos departamentos que comenzaron a andar con graves restricciones económicas, asumiendo y respaldando las asimétricas distribuciones de profesorado para dar respuesta a una nueva realidad a la que todavía permanecen firmemente anclados. Consideremos dos ejemplos para analizar la realidad multifacética de dichos departamentos, el primero lo constituye el de Enfermería, donde se incluye la práctica totalidad del profesorado de la Escuela y el segundo el de Farmacología y Fisiología, con profesorado en dos áreas: Farmacología y Fisiología (Tabla 1) y que comparte una tercera, Bioquímica; imparte materias en cinco centros, en uno de los cuales hay tres licenciaturas y una diplomatura (2).

Concluyendo, la reforma departamental es de índole prioritaria para la adecuada implantación de los grados.

\section{Los equipos docentes}

Son y van a seguir siendo la piedra angular del buen quehacer curricular. Las instituciones deben facilitar el adecuado funcionamiento de los mismos, no sólo con las reformas estructurales pertinentes, sino con una política clara de distribución de funciones de todo el personal perteneciente o integrado en un departamento y con el suficiente apoyo humano reclamado en el apartado de profesorado, así como su correspondiente reconocimiento. Los profesores deben superar las pequeñas diferencias, en el caso en que existan, en aras del reto que esto representa. El tema central de los equipos docentes va a acabar en el alineamiento constructivo de competencias (objetivos-metodología-evaluación). Sin embargo, la argamasa 


\section{TABLA 1.}

Asignaturas de las diferentes licenciaturas/diplomaturas y centros del departamento de Farmacología y Fisiología

\begin{tabular}{|c|c|}
\hline Facultad de Ciencias & ${ }^{*}$ Fundamentos de fisiología animal \\
\hline Licenciatura de Bioquímica: & ${ }^{\star}$ Fisiología ocular y del sistema visual \\
\hline \multicolumn{2}{|l|}{ Licenciatura de Óptica y Optometria } \\
\hline \multicolumn{2}{|l|}{ Facultad Ciencias de la Salud y del Deporte } \\
\hline $\begin{array}{l}\text { Licenciatura de Ciencias } \\
\text { de la Actividad Física y del Deporte: }\end{array}$ & $\begin{array}{l}\text { *Farmacología en el ejercicio físico } \\
\text { *Fisiología del ejercicio } \\
\text { *Fisiología humana } \\
\text { *Practicum }\end{array}$ \\
\hline Licenciatura de Medicina: & $\begin{array}{l}\text { *Biofísica médica } \\
\text { *Bioquímica clínica } \\
\text { *Bioquímica humana } \\
\text { *Farmacología general } \\
\text { *Fisiología humana }\end{array}$ \\
\hline Licenciatura de Odontología: & $\begin{array}{l}\text { *Farmacología } \\
\text { *Fisiología bucodental humana } \\
\text { *Fisiología Humana }\end{array}$ \\
\hline Diplomatura en Nutrición Humana y Dietética: & $\begin{array}{l}\text { *Nutrición clínica y farmacología } \\
\text { *Nutrición y actividad física } \\
\text { *Fisiología humana }\end{array}$ \\
\hline \multicolumn{2}{|l|}{ Facultad de Medicina } \\
\hline Licenciatura de Medicina: & $\begin{array}{l}\text { *Biofísica médica } \\
\text { ”Bioquímica humana } \\
\text { *Bioquímica clínica } \\
\text { ”Farmacología general } \\
\text { *Farmacología clínica } \\
\text { "Fisiología humana }\end{array}$ \\
\hline \multicolumn{2}{|l|}{ Facultad de Veterinaria } \\
\hline Licenciatura de Veterinaria: & $\begin{array}{l}\text { *Biotecnología aplicada a la patología } \\
\text { molecular } \\
\text { *Farmacología, farmacia y terapéutica } \\
\text { *Fisiología animal } \\
\text { *Métodos en Biotecnología } \\
{ }^{*} \text { Neurofisiología }\end{array}$ \\
\hline $\begin{array}{l}\text { Licenciatura de Ciencia y Tecnología } \\
\text { de los Alimentos: }\end{array}$ & *Fisiología \\
\hline \multicolumn{2}{|l|}{ Escuela Universitaria de Ciencias de la Salud } \\
\hline Diplomatura de Fisioterapia: & ${ }^{*}$ Fisiología general \\
\hline Diplomatura de Terapia Ocupacional: & ${ }^{*}$ Fisiología humana \\
\hline
\end{tabular}


con la que van a trabajar es el conocimiento y a él queremos dedicar unas palabras.

\section{El conocimiento}

Se trata del puente de enlace, del eslabón existente entre el profesor y el alumno.

La actividad central de cualquier profesor consiste en mejorar el grado de conocimiento de sus alumnos, asumiendo que ello les ayudará a mejorar/cambiar su conducta desde los planos de su preparación personal y académica.

Cuando nos enfrentamos al tema conocimiento el primer problema que suele plantearse es la disparidad del profesorado frente a una materia o a determinadas partes de la misma. Los estudiantes, no obstante, suelen resolver esta cuestión de un modo aparentemente eficaz: asumen el argumento de autoridad y se adaptan al mismo. Conocimiento es lo que enseña el profesor, o incluso, más concretamente, su profesor en particular y un indicador de mejora es aquello que se determina mediante la evaluación de aquel tipo de conocimiento.

Para evitar estas disparidades se ha llegado en algunas materias a la solución de que cada profesor explique la misma parte al conjunto de alumnos. Sin embargo, no debe perderse de vista que «todo contenido o toda materia enseñada posee diversos grados de profundidad y diversos tipos de conocimiento posibles y cuyo proceso de asimilación requiere diversas estrategias tanto de aprendizaje como de re-aprendizaje por parte de los estudiantes» (1).

Romper con la creencia de que el conocimiento elaborado por el alumno se corresponde con el mismo tipo de conocimiento transmitido por el profesor es la primera labor de cambio. Abordar este tema debe resultar útil para comprender cual es el tipo de conocimiento que se impulsa desde una acción docente determinada y para clarificar el cambio curricular emprendido. 


\section{Tipologías del conocimiento y oportunidades de aprendizaje}

La tabla siguiente, tomada de Rué (1), muestra que todo lo que denominamos «conocimiento» no es de la misma naturaleza. Entre los procedimientos y las teorías, por ejemplo, hay un largo camino. La distinción entre el saber cómo, el saber qué y el saber por qué.

TABLA 2.

Dimensiones, tipos y modalidades de conocimiento

\begin{tabular}{lll}
\hline $\begin{array}{l}\text { Dimensiones del } \\
\text { conocimiento }\end{array}$ & $\begin{array}{l}\text { Tipos de } \\
\text { conocimiento }\end{array}$ & $\begin{array}{l}\text { Modalidades } \\
\text { del mismo }\end{array}$ \\
\hline $\begin{array}{l}\text { Procedimientos, } \\
\text { procesos }\end{array}$ & saber cómo & $\begin{array}{l}\text { Experiencial, } \\
\text { habilidades. }\end{array}$ \\
$\begin{array}{l}\text { Conceptos, pautas, } \\
\text { modelos, relaciones }\end{array}$ & Saber qué & $\begin{array}{l}\text { Temáticas } \\
\text { vinculadas a un } \\
\text { Conocimiento }\end{array}$ \\
$\begin{array}{l}\text { Principios y valores, } \\
\text { teorías }\end{array}$ & Saber por qué & $\begin{array}{l}\text { Formas de } \\
\text { comprensión, de } \\
\text { contextualización. }\end{array}$ \\
\hline
\end{tabular}

El conocimiento se desarrolla en los aprendedores a lo largo de un hipotético eje que va desde los enfoques más superficiales hasta otros más profundos $(3,4)$. La propiedad de ser superficial o profundo no recae tanto en los inputs (lo suministrado) como en el proceso realizado para asimilar el mismo. Los resultados, por lo tanto, no dependen tanto de lo enseñado como del trabajo de explicitación, de elaboración y de reflexión que haga un sujeto con ello, en un contexto de aprendizaje determinado y a partir de cierto tipo de experiencias.

A partir de Bloom y colaboradores, en la década de los cincuenta, se ha aceptado que en el continuo que va entre las nociones de conocimiento superficial y profundo podrían situarse distintas formas de conocer que expresarían otra aproximación de saber. Se han descrito diferentes tipologías del conocimiento. Una de ellas es la de Bauer (4), quien establece una distinción entre dos tipos fundamentales de conocimiento: el de tipo «mapa» y el de tipo «narración». El primer tipo sería el conocimiento de carácter operacional, 
que denominamos científico, al modo de un mapa, en el que la razón de causalidad, su sistema de relaciones, constituye uno de sus rasgos fundamentales. Este tipo de conocimiento se remite al cómo, cómo algo es o funciona. En cambio, el conocimiento de tipo «narración» se remite al porqué, a las razones de algo, incluso a las teorías explicativas de algo.

Para Bauer (4), ambos tipos de conocimiento, mapas y narraciones, constituyen metáforas para ideales más abstractos y todos los tipos actuales del conocimiento humano, incluido el conocimiento científico, son mezclas de conocimientos de ambos tipos, si bien la combinación de ambos difiere en distintos campos de la ciencia. En este sentido, aunque la investigación científica ha desvelado excelentes «mapas», queda mucho conocimiento que aún es sólo narración.

Con la idea de establecer su propuesta de tipología, Bauer (4) establece su clasificación de conocimiento de las ciencias experimentales a lo largo de un continuum que va desde el conocimiento tipo mapa al de carácter narrativo. Todas las aproximaciones manejadas, dice Rue (1), nos remiten a un tipo de resultados de lo que genéricamente se llama aprendizaje. En todas ellas, el grado de conciencia del individuo aparece como crucial, en especial en los tipos de comprensión más elaborados o «profundos». Y para tener un mayor grado de conciencia sobre el conocimiento propuesto es necesario que se den determinadas condiciones en el proceso de su adquisición. Adquirir, tener conciencia o dominar los distintos niveles en un determinado aprendizaje requiere de procesos de experiencia y de reflexión específicos entre los estudiantes. No obstante, se requieren también otros factores: su capacidad individual, lo que sabe, lo que es capaz de hacer en un estadio determinado de su formación. Debe tenerse presente que las capacidades, por sí mismas, son limitadas, pero se expanden en ciertos contextos de oportunidad, a partir de determinadas experiencias y mediante retos que le lleven a desarrollar un pensamiento reflexivo más o menos profundo.

Este es el gran reto de los equipos docentes: la creación de «ambientes enriquecidos» para la enseñanza que permitan expandir las capacidades de los alumnos y hagan de ellos aprendedores profundos y reflexivos. 
Finalmente, como señala Rué (1), el conocimiento no es un efecto que se consigue individualmente, sino que es también un proceso social. Dicho de otra forma, «conocemos» a través de aquellos valores y razonamientos que nos permiten dar valor a la relación que se establece con la fuente del potencial conocimiento, sea del tipo que sea.

Otro importantísimo punto para la reflexión en la línea marcada anteriormente.

\section{Calidad de los procesos de enseñanza}

En Educación Superior, el conocimiento se ha considerado tradicionalmente y considera en nuestro medio como una manifestaciónproducto de la inteligencia y del esfuerzo individual (1). Esta consideración se halla en la base de dos concepciones erróneas: «en primer lugar, hace recaer todo el aprendizaje sobre los contenidos en su versión abstracta, al como ha sido elaborada y presentada por los docentes» y, en segundo, «orienta el aprendizaje hacia las capacidades y esfuerzo individuales» (1).

Estas concepciones han relegado la reflexión sobre las situaciones de aprendizaje al plano de lo «técnico», e incluso de lo «prescindible», puesto que los procesos de enseñanza basados en experiencias, en la calidad de los procesos de apropiación, en la socialización, etc..., son poco relevantes. Hoy, a pesar de la tradición, no podemos sostener dicho sistema de creencias, dice Rué (1), con quien estamos totalmente de acuerdo.

La adquisición del conocimiento es el resultado de un proceso interno y complejo en el que, además de la capacidad del estudiante (aprendiz), intervienen las competencias que ha desarrollado y que se hallan condicionadas por la calidad del propio proceso de aprendizaje. Las aproximaciones actuales a la adquisición del conocimiento la consideran como «el resultado de un determinado tipo de interacción más o menos compleja entre la propia capacidad de aprender del individuo, vinculada a sus experiencias previas, la naturaleza de la situación de aprendizaje presentada y la calidad de las oportunidades para aprender»(1). 
Volvemos a la idea de ambientes estimuladores, de trabajo, enriquecidos, etc. y a la propuesta formal de la eliminación del paradigma reflexivo (de reflexión) de las aulas.

\section{Adquisición del conocimiento y evaluación (control) del mismo}

La confusión entre ambos hechos nace, en opinión de Rué (1) de la reducción que se hace del conocimiento en los actos evaluativos del mismo, cuando éstos se hacen puntualmente al final de un proceso de aprendizaje.

Dichas evaluaciones se orientan hacia un determinado tipo de modelo de aprendizaje y en tanto que son certificativas del progreso curricular tienen una influencia decisiva sobre los estudiantes. La principal, que el tipo de aprendizaje evaluado, mediante el tipo/instrumento de evaluación suministrado se corresponde con los objetivos de aprendizaje de la materia, es decir, «lo que se evalúa y el modo en que se hace definen lo que se ha de aprender de una materia» (1). Y en esto se apoya la actual concepción universitaria de la enseñanza. Se trata del arma de defensa del paradigma reflexivo que el profesor maneja y utiliza como defensa del sistema reinante.

La toma de conciencia de esta confusión permite evitar errores de correspondencia entre lo aprendido y lo evaluado, con consecuencias tan nefastas para sectores importantes del alumnado, ya que ello nada significa de su potencial desarrollo personal e intelectual.

\section{b. EL PERSONAL DE ADMINISTRACIÓN Y SERVICIOS}

Se ha introducido este apartado para poner de manifiesto que esta tarea es función de todos, como lo serán sus logros. Si alguien piensa que Bolonia es cuestión del profesorado camina profundamente equivocado. $Y$ si alguien cree que cada estamento debe caminar con funciones, objetivos y estrategias diferentes es el enemigo dentro del sistema. 


\section{c. LAS INFRAESTRUCTURAS}

Como en la Universidad primitiva éste no es el elemento más importante, pero se trata de un factor de aproximación de primer orden para que los ambientes académico y social se hallen en las mejores condiciones. Para justificar la primera parte de esta expresión el profesor Escanero refiere el siguiente hecho. «Se trata del final de una de nuestras largas conversaciones con el profesor Gambarte de Cardiología de la Facultad de Ciencias Médicas de la Universidad Nacional de Cuyo. Durante un tiempo, el profesor Gambarte venía a nuestro centro para impartir conjuntamente diferentes actividades sobre el Aprendizaje Basado en la Solución de Problemas. Hablando de la reforma y haciéndole ver la dificultad de las clases actuales por su tamaño especialmente, él replicó: "Desengañate, los tabiques que hay que quitar o correr primero son los de la cabeza". Lo mismo me dijo luego cuando hablábamos de la forma, las hileras de sillas y su dificultad para la interacción, la inclinación de anfiteatro romano, etc.». Independientemente de que el factor humano deba ser atendido, pasa otro tanto con el establecimiento de las infraestructuras o marcos adecuados: son necesarios de partida, por su motivación y capacidad estimuladora, aunque insuficientes por sí mismos para obrar cualquier cambio.

\section{Bibliografía}

1. Rué, J. (2009). El aprendizaje autónomo en Educación Superior. Madrid: Narcea SA de Ediciones.

2. Universidad de Zaragoza. Licenciaturas/diplomaturas y centros del departamento de Farmacología y Fisiología. hppt://www.unizar.es/

3. Biggs, J. (1999). Teaching for quality learning at university. SHRE \& Open University Press. Versión en lengua castellana (2006). Calidad del aprendizaje universitario. Madrid: Narcea SA de Ediciones.

4. Bauer, H. H. (1995). Two Kinds of Knowledge. Journal of Scientific Exploration, 9(2), 257-275. 



\section{Capítulo II}

\section{EL ALUMNADO}

Este capítulo comienza con la primera comunicación de un miembro del grupo sobre estilos de aprendizaje de los estudiantes de Medicina hace casi 25 años y la primera aplicación que se hizo en esta Facultad donde se llamó la atención sobre la desestructuración (pérdida de puntuación) en los alumnos de sexto curso con respecto a los de primero y tercero y la recuperación (parcial) en los alumnos MIR (apartado siguiente).

Los resultados presentados posteriormente responden a los objetivos de un proyecto de la AECID que pretende mejorar el currículum desde la perspectiva del cambio de paradigma, centrado en el estudiante (aprendizaje), y tienen un objetivo claro: ofrecer a las Facultades participantes «otra» visión, quizá la misma que ya disponen desde otro ángulo, y a la comunidad universitaria una manera de trabajar en el camino de la reforma curricular. En aquellas deficiencias detectadas, el grupo ofrece las soluciones que le parecen más pertinentes. Pretende, tan sólo, ser un material de trabajo para el debate y la reflexión, que no es poco.

Para su ejecución nos hemos instalado en dos teorías contemporáneas enfoques y estilos de aprendizaje. La justificación es clara, seguimos a Rodríguez Gómez y Grajales Guerra (1) en la misma:

1) ambas teorías han sido clasificadas (2) dentro de los modelos de procesamiento de información y centradas en el aprendizaje, 
2) son teorías no recientes que han ido adquiriendo reconocimiento internacional,

3) utilizan diferente terminología al tratar de identificar la manera de afrontar el aprendizaje y

4) poseen instrumentos de medición que recién se están utilizando en poblaciones de América Latina. Debe incorporarse con justicia que en todo el entorno occidental.

Sería preciso añadir que el grupo tiene plena conciencia de que el currículum se considera en educación como la entidad y noción más holística, inclusiva y abarcadora de entre las manejadas en educación. Este aspecto holístico (globalizador) y comprensivo ha llevado a definirlo como algo que ocurre en la clase, departamento, Facultad de Medicina o Universidad como un todo, extendiéndose más allá de los límites de las transacciones entre profesores y estudiantes a todas las transacciones que tienen lugar en la Facultad de Medicina (3).

Finalmente, los autores quieren y deben hacer otra precisión sobre las herramientas utilizadas: los trabajos sobre fiabilidad y validez sobre los mismos son extremadamente numerosos en educación superior, especialmente en lo que al DREEM, ASSIST y CHAEA se refiere, por lo que no se va a discutir nada al respecto. Si, en cambio, se hará una pequeña concesión en torno a la historia de las herramientas utilizadas para ubicar al lector en el contexto explorador que se ha buscado.

\section{La primera comunicación}

Durante las «II Jornadas de Pedagogía en la Universidad», celebradas en 1986 en la Universidad de Zaragoza, se presentó un primer referente sobre los estilos de aprendizaje de los estudiantes de Medicina (4). Dichos estudiantes tenían la tendencia a usar los siguientes modos cognitivos, definidos según el instrumento utilizado:

a). El modo convergente (converger) $(5,6)$ de los tipos de Kolb, caracterizado por utilizar conceptos abstractos, experimentación activa y razonamientos deductivos; 
b). El modo por principios (principle) de Tamir et al. (7), definido por el hecho de aceptar primariamente la información que ejemplariza un principio científico fundamental; $y$,

c). El modo de campo independiente (field independent) de Goodenough et al. (8), caracterizado porque el proceso de información se fundamenta sobre referencias externas.

En suma, se presentaba el siguiente retrato robot de los estudiantes de Medicina: se trata de individuos de campo independiente, tendentes a la utilización de la experimentación activa, deductivos en la resolución de sus problemas profesionales y que buscan la información de los principios básicos fundamentales (4).

Hasta la actualidad, se concluía (4), las investigaciones realizadas sobre las conductas de aprendizaje de los estudiantes de Medicina han sido limitadas y no han proporcionado un claro perfil que las defina claramente. Uno de los principales problemas ha radicado en la selección de la adecuada instrumentación.

\section{La primera fotofija}

Se incluyen los resultados de esta experiencia (9) porque nos puede poner en antecedentes de la influencia del contexto sobre los estilos de aprendizaje. Se realizó hace más de 20 años, en 1987 concretamente, y participaron los alumnos de primer (79 alumnos), tercer (88 alumnos) y sexto (72 alumnos) cursos de la Facultad de Medicina de Zaragoza. Se utilizaron también los resultados recogidos a 88 médicos internos residentes (MIR) del Hospital Clínico Universitario «Lozano Blesa», representativos de una población total de 108 .

La herramienta utilizada fue el Inventory of Learning Processes descrito, en 1977, por Schmeck, Ribich y Ramanaiah (10). El test, formulado para respuestas de tipo verdadero/falso, consta de 53 ítems, divididos o agrupados en cuatro escalas de procesos de aprendizaje:

- Escala de análisis-síntesis (16 ítems)

- Escala de métodos de estudio (12 ítems) 
— Escala de retención (6 ítems)

- Escala de procesos elaborativos (9 ítems)

Cada ítem explora una conducta que caracteriza a un proceso de aprendizaje. Vg: ¿Memoriza el material que no entiende?.

La escala de análisis-síntesis estima los hábitos que utiliza el encuestado para procesar «en profundidad» la información, así como para conocer los procesos organizativos que posee.

La escala de los métodos de estudio aprecia la «adherencia» a los métodos de estudio tradicionales que son considerados de utilidad en el aprendizaje en los ambientes académicos.

La escala de retención real valora la propensión a la retención detallada de la información factual.

La escala de procesos elaborativos estima los hábitos de estudio para la información codificada, exponiéndola del modo más claro y convincente y reorganizándola como si tuviera que referirla producida por si mismo.

Dicho instrumento se modificó y adaptó a nuestro entorno, reduciendo el número de ítems de que cuenta en su versión original y en vez del SI/NO, como respuesta cualitativa, se introdujeron cuatro posibilidades: Siempre, Casi siempre, Algunas veces, Nunca, valoradas del 1 al 4, con lo que se pudieron cuantificar las respuestas.

El mencionado test se pasó junto con un cuestionario para definir el perfil demográfico y social de los encuestados.

El análisis estadístico de los resultados se realizó en un ordenador VAX 11/780 del Centro de Cálculo de la Universidad de Zaragoza, empleando el programa SPSS. El test utilizado para la comparación de medias fue el de Mann-Whitney-Wilcoxon, aceptando que existían diferencias significativas cuando la p era menor de 0.05 .

Los resultados (puntaje global) de los procesos psicomatéticos se representan en la siguiente tabla. 
TABLA 3.

Evaluación global de los procesos psicomatéticos

\begin{tabular}{lll}
\hline Grupo & Media & Puntuación \\
& 111.22 & D.E. \\
\hline Primer curso & 107.54 & 11.27 \\
Tercer curso & 103.66 & 9.59 \\
Sexto curso & 107.88 & 3.10 \\
MIR & 9.80 \\
\hline
\end{tabular}

Diferencias estadísticamente significativas:

primero y tercero $(p<0.03)$,

primero y sexto $(p<0.002)$,

tercero y sextp $(p<0.03)$,

primero y MIR $(\mathrm{p}<0.02)$ y

sexto y MIR $(p<0.05)$.

En la figura que sigue se representan las variaciones en cada uno de los procesos de que consta la herramienta.

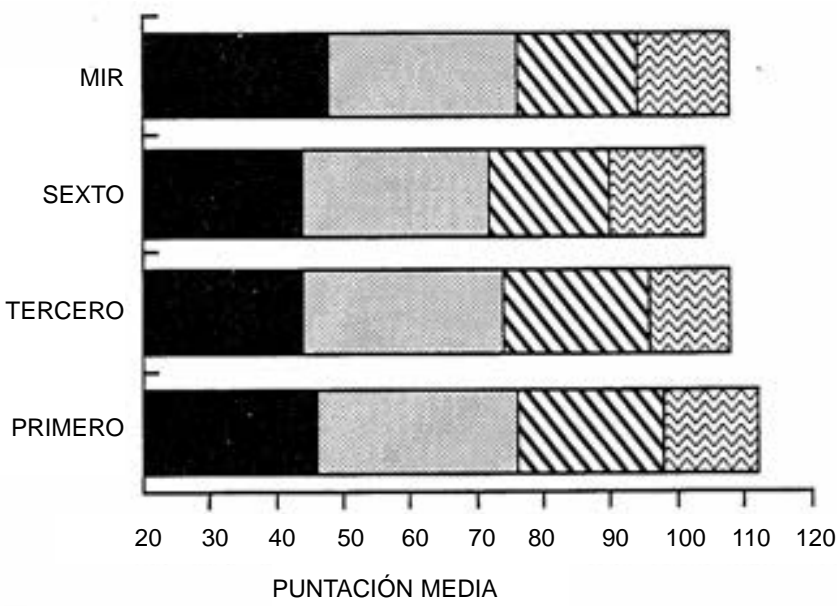

Figura 1. Evaluación global y por escalas. 
Con este trabajo se presentaba por primera vez una fotografía de la variación de los procesos que soportaban el constructo de cada una de las escalas del instrumento a lo largo de la carrera de Medicina. Los resultados no podían ser más llamativos. El paso por la facultad les llevaba a perder puntuación en los mismos, recuperándose, en parte, con el estudio de la especialidad médica. Si bien es cierto que los paradigmas que sustentan ambos tipos de enseñanza son diferentes, el reflexivo en la enseñanza universitaria y el ecológico ambiental, en la de especialidad, los resultados mostrados no podían dejar de ser una llamada a la reflexión por la negativa influencia que se ejercía sobre los estudiantes durante su devenir por la Facultad de Medicina. Las causas, evidentemente, podían ser múltiples, unas intrínsecas: paradigma utilizado, estructura curricular, sistema de evaluación, horarios y organización, etc. y otras extrínsecas a la facultad, como expresión de la desesperanza ante la expectante situación del mercado laboral y de la especialización. En aquel entonces, la plétora de médicos era una realidad y en el examen MIR participaban masas increíbles de estudiantes.

Las características que se iban deteriorando progresivamente conforme avanzaban en sus estudios eran: la capacidad organizativa (un $10 \%$ de los alumnos de sexto curso manifestaba que siempre tenían dificultad en la organización de la información que recordaban), la capacidad de memorización, la evaluación crítica, la capacidad de expresión oral, la planificación de tareas complejas, la capacidad de realizar suposiciones, la capacidad de discernimiento entre distintas informaciones, la resolución de los datos contradictorios procedentes de diferentes fuentes y la capacidad de realizar lecturas críticas.

El perfil obtenido venía a confirmar el reportado para estudiantes de Medicina de otras latitudes con pequeños matices o diferencias, más bien propias de los instrumentos/herramientas utilizados.

\section{Bibliografía}

1. Rodríguez Gómez, J., Grajales Guerra, T. (2007). Modelo de asociación entre los enfoques y estilos de aprendizaje. IX Congreso 
Nacional de Investigación Educativa (área temática 1), Mérida (Yucatán). www.comie.org.mx/congreso/memoria/.../pat.01.htm

2. Cassidy, S. (2004). Learning styles: An overview of theories, models, and measures. Educational Psychology, 24(4), 419-444.

3. Stenhouse, L. (1975). Introduction to Curriculum Research and Development. London, Heinemann.

4. Escanero, J. F. (1986). Procesos psicodidácticos de la enseñanza de la Medicina. Universidad de Zaragoza, Instituto de Ciencias de la Educación. Informes, 21, 77-88.

5. Plovnick, M. S. (1975). Primary care career choices and medical student learning styles. Journal of Medical Education, 50, 849855.

6. Wunderlich, R., Gjerde, C. L. (1978). Another look at Learning Style Inventory and medical career choice. Journal of Medical Education, 53, 45-54.

7. Tamir, P., Schiffman, A., Elstein, A. S., Molidor, J. B., Krupka, J. W. (1979). Development and exploratory trials of a Cognitive Preference Inventory for medical students. Medical Education, 13, 401-406.

8. Goodenough, D. R., Oltman, P. K., Friedman, F., Moore, C. A., Witkin, H. A., Owen, D. R., Raskin, E. (1979). Cognitive styles in the development of medical careers. Journal of Vocational Behavior, 14, 341-351.

9. Escanero, J. F., Puzo, J., Alda, J. O., Soteras, F. (1987). Estilos de aprendizaje de los estudiantes de las Facultades de Medicina (pregrado y postgrado). Universidad de Zaragoza, Instituto de Ciencias de la Educación. Informes, 22 (84 págs).

10. Schmeck, R. R., Ribich, F. D., Ramanaiah, N. (1979). Development of a self report inventory for assessing individual differences in learning processes. Applied Psychological Measurement, 1, 341-351, 1979. 


\section{LOS ANÁLISIS ACTUALES}

En este apartado se presentan los resultados obtenidos con las cuatro herramientas o instrumentos utilizados:

DREEM: análisis de diferentes ambientes, ASSIST: enfoques y estrategias de aprendizaje, CHAEA: estilos de aprendizaje y

CANFIELD: preferencias de estudio y tipología de aprendedor.

\section{Antecedentes sobre estilos}

Para que los estudiantes alcancen buenas notas y aprendan más eficazmente se necesita que se desarrollen las situaciones de aprendizaje más óptimas para ellos. En otras palabras las características individuales de los estudiantes emergen en sus conductas escolares que proporcionan luz sobre como sus mentes trabajan y, en consecuencia, sobre como aprenden. Por consiguiente, «conocer los tipos de experiencias de aprendizaje que los estudiantes valoran más pueden ayudar a los profesores a desarrollar estructuras de cursos alternativos que proporcionen un mejor ajuste entre sus metas y las preferencias de los estilos de aprendizaje de sus estudiantes» (1). Ello nos lleva al planteamiento del alineamiento o emparejamiento de los estilos de aprendizaje del docente y del aprendiz (matching hypothesis). Se trata de un tema que se abordó en el primer libro del grupo (2), adonde remitimos al lector.

\section{DREEM}

\section{Introducción}

a) El ambiente educacional y herramientas para su exploración

La investigación relacionada al ambiente educacional comenzó en la década de los 30 y se vio acelerada por el trabajo de Pace y Stern, en 1958 (3), donde se estudian aspectos relacionados con la 
«atmósfera» en las salas de clases de escuelas (primarias y secundarias) y Universidades utilizando métodos de investigación cualitativa, tales como entrevistas u observación directa al interior de las salas con la intención de capturar las interacciones entre profesores y alumnos en relación al entorno físico.

En 1961, Hutchins (4) publicó uno de los primeros instrumentos específicamente desarrollados para la medición de ambiente educacional en educación médica, el Índice de Ambiente en Escuelas de Medicina (Medical School Environment Index - MSEI) basándose en el trabajo de Stern y Pace (3), que consistió en un cuestionario de 180 ítems y 18 subescalas o dominios.

Varios instrumentos de medición de ambiente educacional fueron creados posteriormente al MSEI. Sin embargo, la mayoría de ellos quedaron obsoletos luego de los profundos cambios conceptuales experimentados en la educación médica a partir de la década del 80 incluyendo: La promoción del aprendizaje activo y una educación centrada en el estudiante con la introducción del aprendizaje basado en problemas, desarrollo de un currículum flexible con cursos obligatorios electivos y la implementación de docencia ambulatoria (5). Uno de los instrumentos desarrollados con posterioridad a estos cambios curriculares y que incorpora los conceptos actuales de un currículo innovador es la encuesta de medición de ambiente educacional de Dundee (Dundee Ready Education Environment Measurement, DREEM), desarrollada por Roff et al. en 1997 (6). Este cuestionario ha sido validado en varios países contando con traducciones a diferentes idiomas incluido el español. El cuestionario DREEM es válido y confiable en la medición del ambiente educacional de pregrado, en particular en las fases iniciales del currículum (ciencias básicas y cursos preclínicos). El cuestionario DREEM también ha sido utilizado en la medición del ambiente educacional de programas de residencia pero no se recomienda su uso en postgrado.

En 1995, Rotem et al. (7), en Australia, identificaron seis variables independientes que se correlacionaban positivamente con el desarrollo profesional: 1. Autonomía y reconocimiento, 2. Claridad en los papeles o funciones a desempeñar, 3. Satisfacción con el trabajo, 4. Calidad de la supervisión, 5 . Apoyo por los pares y 6. Opor- 
tunidades de aprendizaje. Dichas variables no son parte de los aspectos evaluados por los instrumentos desarrollados para pregrado, por lo que se han creado otros instrumentos, que tienen en cuenta las variables identificadas por Rotem et al. (7) para la medición del clima educacional de postgrado, como la encuesta de Medición del Ambiente Educacional del Postgrado Hospitalario (Postgraduate Hospital Education Environment Measure-PHEEM) (8), y otras más específicas para otros ambientes ambientes (quirúrgicos -9- o anestésicos -10-).

\section{b) Concepto y papel en la educación médica}

Para la Real Academia Española (RAE), «clima» es sinónimo de ambiente, aunque incluye un componente de subjetividad que implica la percepción de la persona (alumno) y la actitud del grupo que recibe a dicha persona (profesor y personal administrativo) (11). El «ambiente» es un concepto de gran importancia en el ámbito de las empresas e industrias debido al impacto positivo en la productividad y mejoría de las relaciones interpersonales. Se define como «ambiente» a las condiciones o circunstancias físicas, sociales, económicas, etc., de un lugar, de una reunión, de una colectividad o de una época (11). Este concepto de ambiente laboral se ha ido incorporando progresivamente al mundo educativo. El ambiente educacional es un concepto que cada vez cobra mayor relevancia en la educación médica por su impacto en el proceso de enseñanza, aprendizaje y posterior vida laboral (12).

El currículum es considerado en educación como la entidad y noción más holística, inclusiva y comprensiva. Este aspecto holístico (globalizador) y comprensivo ha llevado a definir el currículum como algo que ocurre en la clase, departamento, Facultad de Medicina o Universidad como un todo (13). Se ha argüido que el currículum se extiende más allá de los límites de las transacciones entre profesores y estudiantes a todas las transacciones que tienen lugar en la Facultad de Medicina. Brady (14), en 1990, expresó el punto de vista de que el nuevo currículum no puede ser razonable separado de su medio de aprendizaje. La manifestación y conceptualización más significativa del currículum es el medio ambiente, 
educacional y organizacional, que abarca todas las cosas que están ocurriendo en las Facultades de Medicina (15). El medio ambiente educativo es uno de los determinantes más importantes de un currículum efectivo. Existe una conexión probada entre el medio ambiente y el logro, satisfacción y éxito de las salidas de los estudiantes (15). Podría concluirse que el estudio del currículum es ampliamente dependiente de los estudios de los medios ambientes que comprende o que están unidos/ligados al mismo. La inferencia es que si uno quiere describir, evaluar o conseguir manejar o tratar con o sobre el currículum de una Facultad de Medicina necesita estudiar el medio ambiente educacional y organizativo o el medio total asociado con él (15).

\section{Material y métodos}

\section{a) Los dos centros de la Universidad de Zaragoza}

La Universidad de Zaragoza tiene dos centros donde se imparte el mismo currículum de Medicina: Zaragoza y Huesca. El entorno educativo podría presentar diferencias debido al tamaño de las clases, al menor número y mejor conocimiento de los estudiantes, profesorado más joven, etc. Ítem más, Huesca, en lo que a Medicina se refiere es un remanente de los antiguos colegios universitarios, que ni creció e independizó, ni clausuró sus estudios.

Con este instrumento se estudiaron y compararon los entornos ambientales de aprendizaje percibidos por los estudiantes en los dos centros de la Universidad donde se estudia Medicina: Zaragoza y Huesca, así como poner de manifiesto las diferencias entre los estudios de Nutrición y Medicina en Huesca. Todo ello para poder actuar sobre las deficiencias detectadas en uno y otro centro con el fín, en última instancia, de incrementar la calidad curricular. Por otra parte, y dado que se han descrito posibles variaciones en la percepción de los ambientes conforme se avanza en los estudios de Medicina se amplió el objetivo incorporando el estudio a los estudiantes de diferentes cursos (primero, tercero y quinto) en dos Facultades: la de Zaragoza y el País Vasco. 


\section{b) Muestra de estudio}

Zaragoza versus Huesca. Ciento cuarenta y cinco estudiantes de primer/segundo curso, 55 pertenecientes a la Facultad de Ciencias de la Salud y el Deporte de Huesca y 90 a la Facultad de Medicina de Zaragoza rellenaron el cuestionario DREEM (Dundee Ready Educational Environment Measure) (6). De los alumnos de Huesca, 28 realizaban los estudios de Nutrición y 27 de Medicina.

Zaragoza versus Bilbao. En este caso se aplicó la encuesta DREEM a 457 estudiantes, 271 de la Facultad de Medicina de la Universidad de Zaragoza y 186 de la del País Vasco. La distribución por cursos fue como sigue: 90/86 estudiantes para el primer año, 77/41 para el tercer año y 104/59 para el quinto año, respectivamente.

\section{c) Herramienta utilizada}

Diferentes metodologías han sido utilizadas para investigar el ambiente (clima) educacional. Recientes estudios han incluido o aproximaciones cualitativas (16) o diferentes cuestionarios (12). De ellos, sólo el cuestionario DREEM (Dundee Ready Educational Environment Measure) es específico para los estudiantes de Medicina y Ciencias de la Salud, en general (6). Este instrumento ha sido desarrollado por una panel internacional y ha sido aplicado en un cierto número de cursos de pregrado de Medicina en diferentes países del mundo (17).

El mencionado cuestionario es un instrumento que mide las percepciones de los estudiantes de los medios ambientes educativos. Consta de un total de 50 ítems y explora cinco «ambientes» diferentes: percepción del aprendizaje -PA- (12 ítems), de la enseñan$\mathrm{za} /$ profesorado -PE- (11 ítems), y autopercepciones del ambiente académico -APAc- (8 ítems), de la atmósfera de aprendizaje (ambiente de aprendizaje) -APAt- (12 ítems) y del ambiente social -APS- ( 7 ítems). Los estudiantes expresan su mejor respuesta sobre una escala de Likert de 5 anotaciones. Así pues, cada ítem puede ser puntuado del 0 al 4, de acuerdo con la siguiente valoración: 4: totalmente de acuerdo; 3: parcialmente de acuerdo; 2 : indiferente/vacilante; 1: en desacuerdo parcial y 0: en total desacuerdo. 
Consecuentemente, la máxima puntuación total que se puede conseguir es 200 puntos. Existen 9 ítems que son expresados negativamente y deben ser contados en sentido inverso: dos en PA (undécima y duodécima), cuatro en PE (séptima, octava, novena y undécima), dos en APAt (undécima y duodécima) y una en APS (tercera).

En la siguiente tabla se presenta una guía aproximativa para la interpretación de cada dominio, como sugieren McAleer y Roff (18).

\section{TABLA 4.}

Guía para la interpretación de las puntuaciones del DREEM

\begin{tabular}{lll}
\hline Dominio & Puntuación & Interpretación \\
\hline PA & $0-12$ & Muy pobre \\
& $13-24$ & La enseñanza es considerada negativamente \\
& $25-36$ & Valoración más positiva \\
& $37-48$ & La enseñanza es altamente considerada \\
& $0-12$ & Abismal \\
PE & $12-22$ & En necesidad de algún reentrenamiento \\
& $23-33$ & Moviéndose en la dirección correcta \\
& $34-44$ & Profesores modelo \\
APAt & $0-12$ & Un medio ambiente horroroso \\
& $13-24$ & Existen muchos puntos que necesitan cambios \\
& $25-36$ & Atmósfera más positiva \\
& $37-48$ & Una buena sensación de todo \\
APAc & $0-8$ & Sentimiento de fracaso total \\
& $9-16$ & Muchos aspectos negativos \\
& $17-24$ & Sentimientos hacia el lado positivo \\
& $25-32$ & Confidente \\
APS & $0-7$ & Miserable \\
& $8-14$ & No como lugar agradable \\
& $15-21$ & No demasiado malo \\
& $22-28$ & Muy bueno socialmente \\
& &
\end{tabular}

Con respecto a la interpretación de la puntuación global de la herramienta la siguiente guía puede ser útil:

entre $0-50$ muy pobre, entre 51 - 100 con muchos problemas, entre 101 - 150 más positivo que negativo y entre $151-200$ excelente. 
El DREEM también puede ser utilizado para precisar más específicamente las fortalezas y debilidades en un determinado ambiente educativo. Para ello se necesita analizar las respuestas a nivel individual. Los ítems con una media de puntuación de 3.5 ó superior son considerados altamente positivos. Cualquier ítem con una media de 2 ó inferior debería ser examinado más estrechamente ya que indican áreas con problemas. Ítems con una media entre 2 y 3 son aspectos ambientales que deberían ser mejorados.

Dos advertencias, no obstante, deben tenerse presentes:

En primer lugar, ha de asumirse que el cuestionario utilizado no proporciona las razones subyacentes que expliquen las respuestas de los estudiantes.

En segundo, como indica Till (19), este cuestionario ha sido usado para comparar diferentes Facultades de Medicina pero no presenta el tratamiento a seguir para modificar el clima de estudio detectado y, por supuesto, menos todavía, indicaciones u orientaciones, para decidir sobre aspectos de planificación universitaria.

\section{d) Estadistica}

Las diferencias en el aprendizaje fueron analizadas mediante una t-Student para muestras independientes. El nivel de significación se estableció en $P<0,05$.

\section{Resultados}

a). Medicina vs Nutrición (Huesca): No se encontraron diferencias significativas en la autopercepción de los estudiantes en Nutrición y Medicina de Huesca en ninguno de los ambientes explorados.

b). Medicina: Zaragoza vs Huesca. Se ha observado un aumento significativo en todas las percepciones de los ambientes analizados en Zaragoza. La puntuación total fue para Zaragoza de $141.8+$ +/1.36 puntos y para Huesca de $122.3+/-1.93$ puntos.

A continuación se presentan los resultados correspondientes a cada uno de los ambientes explorados. 
TABLA 5.

Puntuación de los estudiantes de Medicina

(Zaragoza y Huesca) en la percepción del aprendizaje

\begin{tabular}{|c|c|c|c|}
\hline \multicolumn{4}{|c|}{ Percepción del estudiante acerca del aprendizaje } \\
\hline Ítems & Zaragoza & Huesca $P$ & Prueba $t(P)$ \\
\hline Me siento motivado a participar en clases & $2,8 \pm 0,1$ & $2,6 \pm 0,1$ & 0,204 \\
\hline $\begin{array}{l}\text { La enseñanza se preocupa por desarrollar } \\
\text { mi auto-confianza }\end{array}$ & $2,4 \pm 0,1$ & $1,9 \pm 0,1$ & 0,005 \\
\hline $\begin{array}{l}\text { La enseñanza me anima a ser } \\
\text { un aprendedor activo }\end{array}$ & $2,9 \pm 0,08$ & $2,7 \pm 0,12$ & 0,330 \\
\hline La enseñanza está bien enfocada & $2,6 \pm 0,09$ & $2,2 \pm 0,1$ & 0,005 \\
\hline $\begin{array}{l}\text { La enseñanza se preocupa por desarrollar } \\
\text { mis competencias }\end{array}$ & $2,9 \pm 0,08$ & $2,1 \pm 0,1$ & 0,001 \\
\hline $\begin{array}{l}\text { Los objetivos de aprendizaje del curso } \\
\text { me han quedado claros }\end{array}$ & $3,1 \pm 0,8$ & $2,9 \pm 0,08$ & 0,152 \\
\hline La enseñanza es a menudo estimulante & $2,8 \pm 0,1$ & $2,6 \pm 0,1$ & 0,330 \\
\hline $\begin{array}{l}\text { La distribución/programación horaria de } \\
\text { clases está bien organizada }\end{array}$ & $2,3 \pm 0,12$ & $0,5 \pm 0,09$ & 0,001 \\
\hline La enseñanza está centrada en el estudiante & $2,8 \pm 0,1$ & $2,2 \pm 0,12$ & 0,003 \\
\hline $\begin{array}{l}\text { La enseñanza a largo plazo esta privilegiada } \\
\text { sobre la de corto plazo }\end{array}$ & $2,6 \pm 0,1$ & $2,4 \pm 0,11$ & 0,347 \\
\hline La enseñanza está muy centrada en el profesor & $2,1 \pm 0,11$ & $2,0 \pm 0,1$ & 0,397 \\
\hline $\begin{array}{l}\text { La enseñanza sobre enfatiza el aprendizaje } \\
\text { de hechos concretos }\end{array}$ & $1,5 \pm 0,1$ & $2,2 \pm 0,09$ & 0,001 \\
\hline TOTAL & $30,8 \pm 0,48$ & $26,3 \pm 0,63$ & $3 \quad 0,0001$ \\
\hline
\end{tabular}

Los resultados de este primer ambiente (aprendizaje), con respecto a Zaragoza, indican un puntaje bastante superior al de Huesca.

En Zaragoza existen varios puntos para mejorar: dejar de centrar la enseñanza en el profesorado, dejar de sobreenfatizar en el aprendizaje de hechos concretos, conseguir una mejor programación y mejorar la autoconfianza de los estudiantes. En Huesca son varios más y algunos con características alarmantes: como la programación horaria que, como se conoce bien a todos los niveles universitarios, viene a satisfacer las necesidades del profesorado, no 
TABLA 6.

Puntuación de los estudiantes de Medicina (Zaragoza y Huesca) en la percepción de los profesores (enseñanza)

\begin{tabular}{llll}
\hline \multicolumn{4}{c}{ Percepción que tiene el estudiante de los profesores } \\
\hline Ítems & Zaragoza & Huesca & Prueba t $(\boldsymbol{P})$ \\
\hline $\begin{array}{l}\text { Los profesores son buenos facilitando } \\
\text { retroalimentación a los estudiantes }\end{array}$ & $2,6 \pm 0,09$ & $2,4 \pm 0,09$ & 0,126 \\
$\begin{array}{l}\text { Los profesores tienen muy buenas habilidades } \\
\text { de comunicación con los pacientes }\end{array}$ & $2,5 \pm 0,08$ & $2,3 \pm 0,09$ & 0,211 \\
Los profesores son identificables & $3,0 \pm 0,08$ & $3,1 \pm 0,07$ & 0,633 \\
Los profesores dan ejemplos claros & $3,0 \pm 0,07$ & $2,6 \pm 0,09$ & 0,019 \\
Los profesores están bien preparados & $3,0 \pm 0,08$ & $2,4 \pm 0,09$ & 0,001 \\
para sus clases & & & \\
Los profesores proporcionan crítica constructiva & $2,6 \pm 0,09$ & $2,4 \pm 0,1$ & 0,131 \\
Los profesores ridiculizan a los estudiantes & $2,8 \pm 0,1$ & $0,6 \pm 0,11$ & 0,001 \\
Los profesores se molestan en clases & $1,9 \pm 0,11$ & $1,3 \pm 0,12$ & 0,001 \\
Los profesores son autoritarios & $1,7 \pm 0,11$ & $1,4 \pm 0,13$ & 0,142 \\
Los profesores son pacientes con los enfermos & $2,5 \pm 0,08$ & $2,7 \pm 0,07$ & 0,160 \\
Los estudiantes irritan a los profesores & $2,2 \pm 0,11$ & $0,8 \pm 0,12$ & 0,001 \\
\hline TOTAL & $\mathbf{2 7 , 4} \pm \mathbf{0 , 4 6}$ & $\mathbf{2 1 , 6 \pm 0 , 6}$ & $\mathbf{0 , 0 0 0 1}$ \\
\hline
\end{tabular}

de la enseñanza. Huesca, aparte de los ítems de Zaragoza, necesita mejorar en unos cuantos más.

En el ambiente enseñanza/profesorado Zaragoza presenta algunos hechos que los estudiantes nos han manifestado privadamente en varias ocasiones: los profesores se molestan en las clases, son autoritarios y los estudiantes irritan a los profesores. Tarea importante que se necesita abordar tras un debate serio del profesorado. En Huesca todavía parece peor esta situación. 
TABLA 7.

Puntuación de los estudiantes de Medicina (Zaragoza y Huesca) en la auto percepción del ambiente académico

\begin{tabular}{|c|c|c|c|}
\hline \multicolumn{4}{|c|}{ Autopercepción académica del estudiante } \\
\hline Ítems & Zaragoza & Huesca $\mathbf{P}$ & Prueba $\mathrm{t}(P)$ \\
\hline Soy capaz de memorizar todo lo que necesito & $3,1 \pm 0,09$ & $2,8 \pm 0,09$ & 0,061 \\
\hline $\begin{array}{l}\text { Mucho de lo que tengo que aprender parece } \\
\text { relevante en la carrera de Medicina }\end{array}$ & $2,7 \pm 0,1$ & $2,7 \pm 0,1$ & 0,988 \\
\hline $\begin{array}{l}\text { Considero que me están formando bien } \\
\text { para mi desempeño profesional }\end{array}$ & $3,0 \pm 0,09$ & $2,8 \pm 0,1$ & 0,308 \\
\hline $\begin{array}{l}\text { El trabajo del gestión académica anterior (2007) } \\
\text { ha sido una buena preparación para el trabajo } \\
\text { de éste año }\end{array}$ & $2,9 \pm 0,07$ & $2,4 \pm 0,11$ & 0,001 \\
\hline $\begin{array}{l}\text { Mis habilidades en la solución de problemas } \\
\text { están siendo bien desarrolladas }\end{array}$ & $2,7 \pm 0,09$ & $2,6 \pm 0,07$ & 0,828 \\
\hline Confío en aprobar éste curso (gestión 2008) & $3,6 \pm 0,07$ & $3,6 \pm 0,05$ & 0,827 \\
\hline $\begin{array}{l}\text { He aprendido mucho acerca de empatía } \\
\text { en mi profesión }\end{array}$ & $2,6 \pm 0,1$ & $2,7 \pm 0,1$ & 0,603 \\
\hline $\begin{array}{l}\text { Estrategias de aprendizaje que antes me } \\
\text { funcionaron, continúan funcionando }\end{array}$ & $2,9 \pm 0,11$ & $3,0 \pm 0,08$ & 0,600 \\
\hline TOTAL & $23,5 \pm 0,43$ & $22,6 \pm 0,47$ & $7 \quad 0,01$ \\
\hline
\end{tabular}

En este ambiente los resultados muestran que en ambos centros todos los aspectos tratados son bastante aceptables, aunque alguno susceptible de mejora. 
TABLA 8.

Puntuación de los estudiantes de Medicina (Zaragoza y Huesca) en la autopercepción del ambiente de aprendizaje

\begin{tabular}{lccc}
\hline \multicolumn{4}{c}{ Percepción del estudiante acerca del ambiente de aprendizaje } \\
\hline Ítems & Zaragoza & Huesca & Prueba t $(\boldsymbol{P})$ \\
\hline El ambiente en las clases es agradable & $3,5 \pm 0,07$ & $3,3 \pm 0,07$ & 0,065 \\
Puedo preguntar lo que quiero & $3,1 \pm 0,09$ & $3,4 \pm 0,07$ & 0,036 \\
Me siento socialmente cómodo en la clase & $3,4 \pm 0,07$ & $3,5 \pm 0,06$ & 0,598 \\
$\begin{array}{l}\text { Tengo oportunidades para desarrollar habilidades } \\
\text { interpersonales }\end{array}$ & $3,3 \pm 0,07$ & $3,0 \pm 0,06$ & 0,045 \\
El ambiente durante los seminarios/tutorías & $3,3 \pm 0,06$ & $2,8 \pm 0,1$ & 0,001 \\
es agradable & & & \\
El placer de estudiar en el curso en el que estoy & $2,8 \pm 0,11$ & $2,5 \pm 0,12$ & 0,153 \\
es mayor que el estrés que esto produce & & & \\
El ambiente motiva mi aprendizaje & $3,0 \pm 0,09$ & $2,5 \pm 0,11$ & 0,003 \\
Soy capaz de concentrarme bien & $3,0 \pm 0,09$ & $3,0 \pm 0,08$ & 0,796 \\
El ambiente en el aula es agradable & $3,4 \pm 0,08$ & $3,2 \pm 0,07$ & 0,243 \\
El curso en el que estoy tiene, sus tiempos & $2,6 \pm 0,1$ & $1,3 \pm 0,13$ & 0,001 \\
adecuadamente programados & & & \\
Encuentro la experiencia decepcionante & $3,5 \pm 0,07$ & $0,5 \pm 0,09$ & 0,001 \\
El copiar en las evaluaciones es frecuente & $2,9 \pm 0,11$ & $1,4 \pm 0,07$ & 0,001 \\
en este curso. & & & $\mathbf{0 , 0 0 0 1}$ \\
\hline TOTAL & $\mathbf{3 7 , 8} \mathbf{0 , 5 5}$ & $\mathbf{3 2 , 6} \mathbf{0 , 5 8}$ & $\mathbf{0}$ \\
\hline
\end{tabular}

En la valoración del ambiente de aprendizaje Zaragoza no precisa de mejoras o correcciones. En cambio, en Huesca, los alumnos vuelven a insistir en la adecuada programación, en hacer menos decepcionante su paso por la facultad y en que suelen copiar en las evaluaciones. 
TABLA 9.

Puntuación de los estudiantes de Medicina (Zaragoza y Huesca) en la autopercepción del ambiente social del estudiante

\begin{tabular}{lccc}
\hline \multicolumn{4}{c}{ Auto-percepción social del estudiante } \\
\hline Ítems & Zaragoza & Huesca & Prueba t $(\boldsymbol{P})$ \\
\hline $\begin{array}{l}\text { Tengo buenos amigos en el curso en el que estoy } \\
\text { en la Facultad de Medicina }\end{array}$ & $3,7 \pm 0,06$ & $3,7 \pm 0,05$ & 0,334 \\
$\begin{array}{l}\text { Existe un buen sistema de apoyo para los } \\
\text { estudiantes que se estresan }\end{array}$ & $2,1 \pm 0,11$ & $1,4 \pm 0,11$ & 0,001 \\
Estoy muy cansado para disfrutar del curso & $2,7 \pm 0,11$ & $1,2 \pm 0,11$ & 0,001 \\
Rara vez me aburro en este curso & $2,3 \pm 0,12$ & $2,4 \pm 0,1$ & 0,512 \\
Mi alojamiento (vivienda) es agradable & $3,7 \pm 0,07$ & $3,5 \pm 0,06$ & 0,500 \\
Mi vida social es buena & $3,7 \pm 0,06$ & $3,7 \pm 0,06$ & 0,476 \\
Rara vez me siento solo & $3,3 \pm 0,1$ & $3,3 \pm 0,11$ & 0,995 \\
\hline TOTAL & $\mathbf{2 1 , 5 \pm 0 , 3 4}$ & $\mathbf{1 9 , 2} \pm \mathbf{0 , 3 3}$ & $\mathbf{0 , 0 1}$ \\
\hline
\end{tabular}

Respecto al ambiente social, llama la atención, en Zaragoza, el que no reconozcan un buen sistema de apoyo a los estudiantes que se estresan y que se aburren. Los alumnos de Huesca tienen el mismo problema más exacerbado y sobre todo el reconocimiento de que están cansados. Para todos estos puntos deberían establecerse medidas correctoras en ambas ciudades.

En la siguiente tabla se indica la valoración que merecen las puntuaciones obtenidas en cada uno de los ambientes en Zaragoza y Huesca. 
TABLA 10.

Puntuación de los estudiantes de Medicina (Zaragoza y Huesca) y su valoración en la percepción del ambiente

\begin{tabular}{lcc}
\hline $\begin{array}{l}\text { Medio ambiente } \\
\text { Ciudad }\end{array}$ & Puntuación & Valoración \\
\hline $\begin{array}{l}\text { Percepción del aprendizaje } \\
\text { Zaragoza }\end{array}$ & 30.8 & $\begin{array}{c}\text { Valoración positiva } \\
\text { id. }\end{array}$ \\
$\begin{array}{l}\text { Huesca } \\
\text { Percepción de la enseñanza }\end{array}$ & 26.3 & Dirección correcta \\
$\begin{array}{l}\text { Zaragoza } \\
\text { Huesca }\end{array}$ & 27.4 & Algún reentrenamiento \\
$\begin{array}{l}\text { Percepción académica } \\
\text { Zaragoza }\end{array}$ & 21.6 & Positivo - Confidente \\
Huesca & & id. \\
$\begin{array}{l}\text { Percepción de la atmósfera } \\
\begin{array}{l}\text { Zaragoza } \\
\text { Huesca }\end{array}\end{array}$ & 23.5 & Buena sensación de todo \\
$\begin{array}{l}\text { Percepción social } \\
\text { Zaragoza }\end{array}$ & 37.8 & Positiva \\
Huesca & 32.6 & No demasiado malo \\
\hline
\end{tabular}

c). Medicina: Zaragoza vs País Vasco. En los tres cursos analizados las puntuaciones totales del DREEM fueron significativamente mayores en la Universidad de Zaragoza. Esto se explica por una mejor percepción en lo que se refiere al aprendizaje, los profesores y el clima educacional. En términos generales la percepción del ambiente educacional en la Universidad de Zaragoza cae en el 5 . $^{\circ}$ año. En cambio, en la del País Vasco, esta percepción aumenta en $3 .^{\circ}$ y $5 .^{\circ}$ año. 


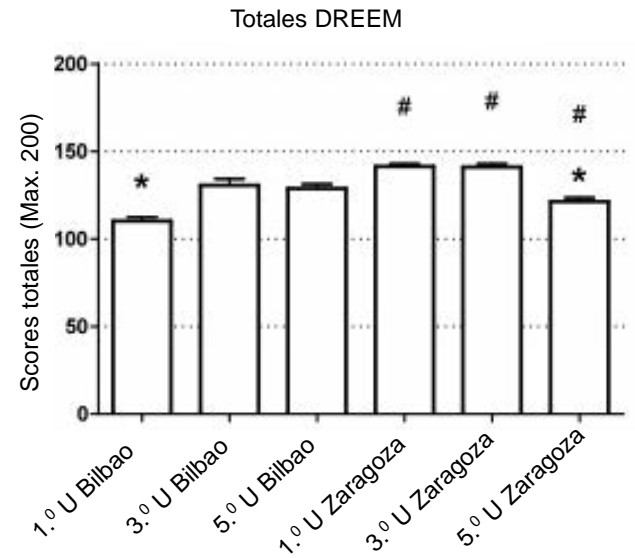

Figura 2. Puntuaciones totales de los medios ambientes educativos explorados de los alumnos de 1.ำ 3. y 5. cursos de las Facultades de Medicina de Zaragoza y Bilbao
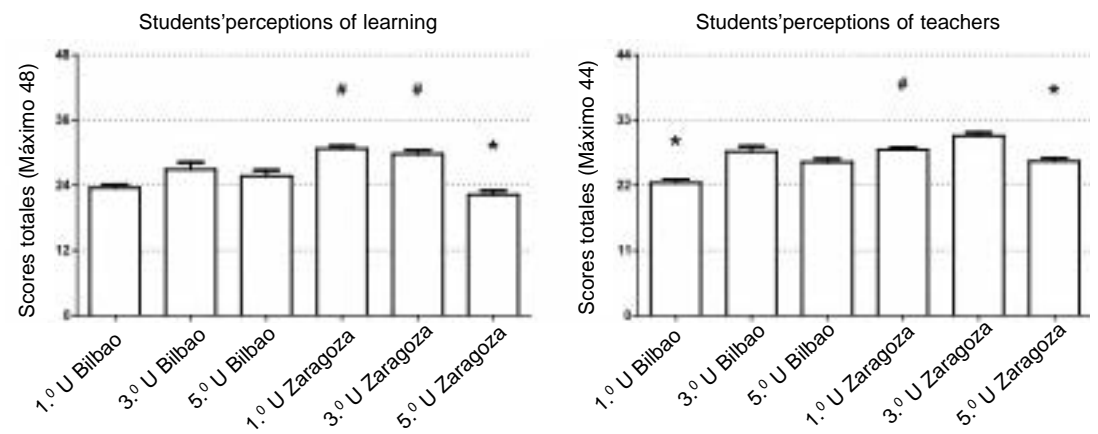

Figura 3. Puntuaciones en cada uno de los medios ambientes educativos explorados de los alumnos de $1 .^{\circ}, 3 .^{\circ}$ y $5 .^{\circ}$ cursos de las Facultades de Medicina de Zaragoza y Bilbao. 

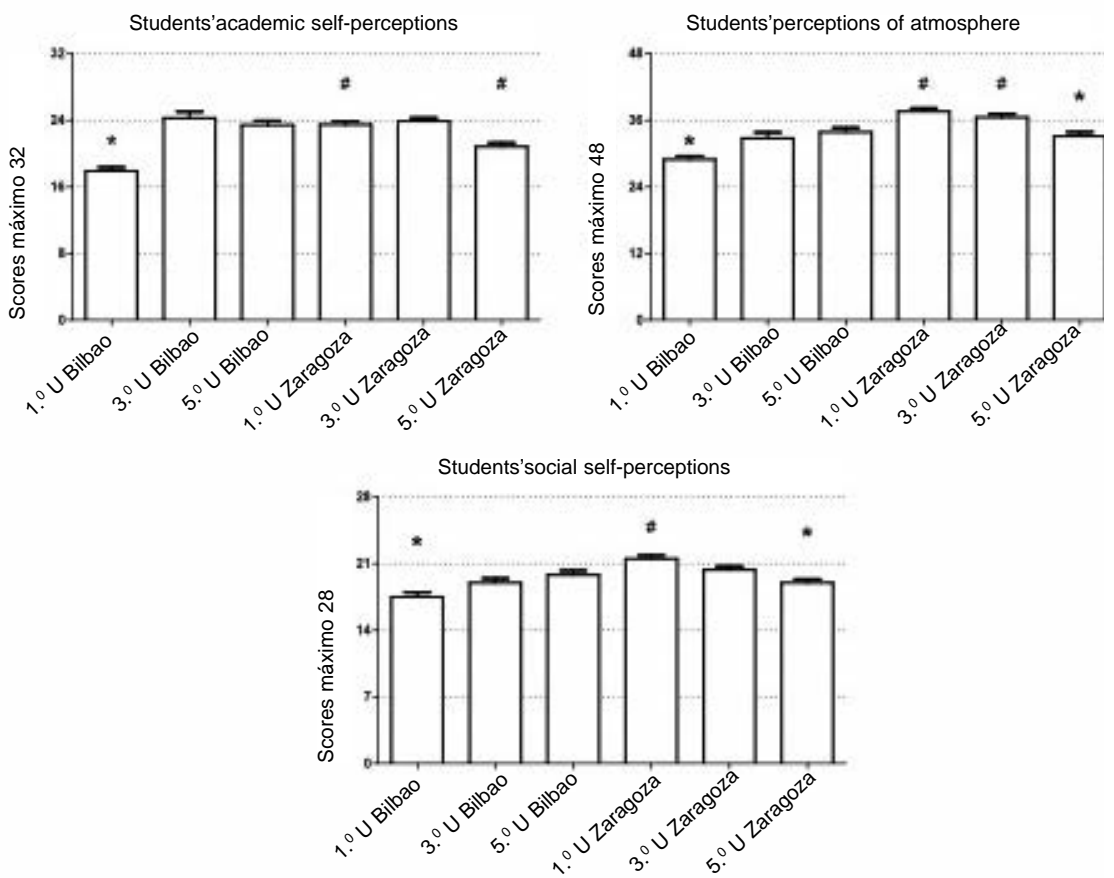

Figura 4. Puntuaciones en cada uno de los medios ambientes educativos explorados de los alumnos de $1 .^{\circ}, 3 .^{\circ}$ y $5^{\circ}$ cursos de las Facultades de Medicina de Zaragoza y Bilbao.

En general, de los estudiantes de Zaragoza podría decirse que las puntuaciones correspondientes a las percepciones del aprendizaje y la enseñanza (profesores) pueden y deben mejorarse, mientras que el resto de ambientes académico, atmósfera de aprendizaje y social presentan una puntuación considerablemente buena. Dos hechos deben considerarse: uno, el llamativo y significativo descenso en todos los ambientes explorados cuando los alumnos llegan al quinto curso y dos, la puntuación del aprendizaje y profesores hacen que el total quede en el sector de entre 101-150.

El patrón de comportamiento de los alumnos de Bilbao es completamente diferente: En algunos ambientes aumenta la puntuación media de los alumnos de tercero y quinto con respecto a los de primero (aprendizaje, profesores y autopercepciones académicas) y en 
otros casos aumenta progresivamente conforme avanzan en los estudios de la carrera (autopercepciones de la atmósfera y social). Los alumnos que mejor valoran los ambientes son los de tercer curso.

Comparativamente (Zaragoza versus Bilbao) y de manera global, los alumnos de primero y tercer cursos de Zaragoza proporcionan puntuaciones más altas. Específicamente, resultan llamativas las puntuaciones de los alumnos de primero y tercero en la percepción del aprendizaje, no así en los de quinto. Un hecho similar, menos pronunciado ocurre en la atmósfera y social siendo más parecidos en los profesores y autopercepciones académicas (con excepción de los grupos con menores puntuaciones en ambas Facultades: los de primero en Bilbao y los de quinto en Zaragoza).

Un análisis más detallado por cuestiones y referido solamente a Zaragoza, por ambientes, se va a proceder a indicar aquellos aspectos que necesitan de mejora específica:

TABLA 11.

Puntuaciones de los alumnos de $10^{\circ}, 3 .^{\circ}$ y $5^{\circ}$ de la Facultad de Medicina de la Universidad de Zaragoza

\begin{tabular}{|c|c|c|c|c|c|c|}
\hline & \multicolumn{6}{|c|}{ U de Zaragoza } \\
\hline & \multicolumn{2}{|c|}{$1 .^{\circ}$} & \multicolumn{2}{|c|}{$3 .^{\circ}$} & \multicolumn{2}{|c|}{$5 .^{\circ}$} \\
\hline & Prom & ES & Prom & ES & Prom & ES \\
\hline I Registrar's Perception of Learning & 30,7 & 0,48 & 29,8 & 0,66 & 22,3 & 0,73 \\
\hline Me siento motivado a participar en clases & 2,8 & 0,10 & 2,4 & 0,10 & 1,8 & 0,11 \\
\hline $\begin{array}{l}\text { La enseñanza se preocupa por desarrollar } \\
\text { mi autoconfianza }\end{array}$ & 2,4 & 0,10 & 2,1 & 0,12 & 1,5 & 0,11 \\
\hline $\begin{array}{l}\text { La enseñanza me anima a ser un } \\
\text { aprendedor activo }\end{array}$ & 2,9 & 0,08 & 2,7 & 0,12 & 1,7 & 0,11 \\
\hline La enseñanza está bien enfocada & 2,6 & 0,09 & 2,5 & 0,11 & 1,7 & 0,11 \\
\hline $\begin{array}{l}\text { La enseñanza se preocupa por desarrollar } \\
\text { mis competencias }\end{array}$ & 2,9 & 0,08 & 2,6 & 0,11 & 2,1 & 0,11 \\
\hline $\begin{array}{l}\text { Los objetivos de aprendizaje del curso } \\
\text { me han quedado claros }\end{array}$ & 3,1 & 0,08 & 3,1 & 0,09 & 2,8 & 0,10 \\
\hline La enseñanza es a menudo estimulante & 2,8 & 0,10 & 2,5 & 0,12 & 2,0 & 0,11 \\
\hline $\begin{array}{l}\text { La programación horaria está bien } \\
\text { organizada }\end{array}$ & 2,3 & 0,12 & 2,9 & 0,11 & 2,2 & 0,14 \\
\hline
\end{tabular}




\begin{tabular}{|c|c|c|c|c|c|c|}
\hline $\begin{array}{l}\text { La enseñanza está centrada } \\
\text { en el estudiante }\end{array}$ & 2,8 & 0,10 & 2,9 & 0,11 & 1,7 & 0,11 \\
\hline $\begin{array}{l}\text { Se enfatiza la enseñanza a largo plazo } \\
\text { por sobre la de corto plazo }\end{array}$ & 2,6 & 0,10 & 2,6 & 0,11 & 1,8 & 0,10 \\
\hline $\begin{array}{l}\text { La enseñanza está demasiado centrada } \\
\text { en el profesor }\end{array}$ & 2,1 & 0,11 & 1,9 & 0,11 & 1,3 & 0,10 \\
\hline $\begin{array}{l}\text { La enseñanza sobreenfatiza el aprendizaje } \\
\text { de hechos concretos }\end{array}$ & 1,5 & 0,10 & 1,8 & 0,10 & 1,6 & 0,10 \\
\hline
\end{tabular}

\begin{tabular}{|c|c|c|c|c|c|c|}
\hline $\begin{array}{l}\text { II Registrar's Perception of Course } \\
\text { organisers }\end{array}$ & 28,0 & 0,46 & 30,3 & 0,55 & 26,1 & 0,52 \\
\hline $\begin{array}{l}\text { Los profesores son buenos facilitando } \\
\text { retroalimentación a los estudiantes }\end{array}$ & 2,6 & 0,09 & 2,5 & 0,10 & 1,7 & 0,09 \\
\hline $\begin{array}{l}\text { Los profesores tienen habilidad para } \\
\text { relacionarse con los pacientes }\end{array}$ & 2,5 & 0,08 & 2,8 & 0,08 & 2,3 & 0,09 \\
\hline Los profesores son identificables & 3,0 & 0,08 & 3,1 & 0,09 & 2,7 & 0,09 \\
\hline Los profesores dan ejemplos claros & 3,0 & 0,07 & 3,0 & 0,08 & 2,6 & 0,09 \\
\hline $\begin{array}{l}\text { Los profesores están bien preparados } \\
\text { para sus clases }\end{array}$ & 3,0 & 0,08 & 3,2 & 0,07 & 2,9 & 0,08 \\
\hline $\begin{array}{l}\text { Los profesores proporcionan crítica } \\
\text { constructiva }\end{array}$ & 2,6 & 0,09 & 2,6 & 0,10 & 2,0 & 0,10 \\
\hline Los profesores ridiculizan a los estudiantes & 2,8 & 0,10 & 3,1 & 0,11 & 2,7 & 0,12 \\
\hline Los profesores se molestan en clases & 1,9 & 0,11 & 2,4 & 0,12 & 2,3 & 0,10 \\
\hline Los profesores son autoritarios & 1,7 & 0,11 & 2,2 & 0,12 & 1,8 & 0,11 \\
\hline $\begin{array}{l}\text { Los profesores tienen paciencia frente } \\
\text { a los enfermos }\end{array}$ & 2,5 & 0,08 & 2,7 & 0,07 & 2,5 & 0,08 \\
\hline Los estudiantes irritan a los profesores & 2,2 & 0,11 & 2,8 & 0,12 & 2,7 & 0,12 \\
\hline III Registrar's Academic Self Perceptions & 23,5 & 0,43 & 23,9 & 0,39 & 20,8 & 0,45 \\
\hline $\begin{array}{l}\text { Soy capaz de memorizar todo lo que } \\
\text { necesito }\end{array}$ & 3,1 & 0,09 & 3,0 & 0,08 & 2,5 & 0,10 \\
\hline $\begin{array}{l}\text { Mucho de lo que aprendo parece relevante } \\
\text { en la carrera de Medicina }\end{array}$ & 2,7 & 0,10 & 2,8 & 0,10 & 2,3 & 0,11 \\
\hline $\begin{array}{l}\text { Considero que me están formando bien } \\
\text { para mi profesión }\end{array}$ & 3,0 & 0,09 & 2,9 & 0,09 & 2,0 & 0,11 \\
\hline $\begin{array}{l}\text { Lo aprendido el año pasado ha sido una } \\
\text { buena preparación para aprender este año }\end{array}$ & 2,9 & 0,07 & 2,9 & 0,09 & 2,3 & 0,09 \\
\hline $\begin{array}{l}\text { Mis habilidades en la solución de problemas } \\
\text { están siendo bien desarrolladas }\end{array}$ & 2,7 & 0,09 & 2,8 & 0,09 & 2,3 & 0,10 \\
\hline Confío en aprobar este año & 3,6 & 0,07 & 3,4 & 0,07 & 3,8 & 0,05 \\
\hline
\end{tabular}


He aprendido mucho acerca de empatía en mi profesión

Las estrategias de aprendizaje que antes me funcionaron, continúan funcionando
$2,6 \quad 0,10$
2,9
0,11
$2,7 \quad 0,10$
$2,9 \quad 0,12$
$3,2 \quad 0,09$
3,0
0,09

\section{Registrar's Perception of Atmosphere}

El ambiente en las clases es relajado

$3,5 \quad 0,07$

Puedo preguntar lo que quiero

Me siento socialmente cómodo en clases

Tengo oportunidades para desarrollar

habilidades interpersonales

El ambiente durante los seminarios es relajado

El placer de estudiar medicina es mayor que el estrés que esto produce

El ambiente motiva mi aprendizaje

$3,1 \quad 0,09$

$3,4 \quad 0,07$

$3,3 \quad 0,07$

$3,3 \quad 0,06$

3,0

$2,8 \quad 0,11$

2,4

0,13

2,1

0,11

Soy capaz de concentrarme adecuadamente 3,0

$3,0 \quad 0,09$

$2,8 \quad 0,10$

$2,3 \quad 0,11$

El ambiente de aprendizaje es agradable

$3,4 \quad 0,08$

$3,0 \quad 0,09$

$3,0 \quad 0,09$

La escuela tiene los tiempos adecuadamente 2,6 $\quad 0,10$ programados

Encuentro decepcionante la experiencia de aprendizaje

La copia en las pruebas es habitual en esta escuela

$\begin{array}{llllll}3,5 & 0,07 & 3,3 & 0,11 & 2,9 & 0,11 \\ 2,9 & 0,11 & 3,0 & 0,12 & 2,9 & 0,11\end{array}$

\begin{tabular}{lcccccc}
\hline V Registrar's Social Self Perceptions & $\mathbf{2 1 , 5}$ & $\mathbf{0 , 3 5}$ & $\mathbf{2 0 , 4}$ & $\mathbf{0 , 3 8}$ & $\mathbf{1 9 , 0}$ & $\mathbf{0 , 3 6}$ \\
\hline Tengo buenos amigos en esta facultad & 3,7 & 0,06 & 3,6 & 0,09 & 3,6 & 0,08 \\
Existe un buen sistema de apoyo para & 2,1 & 0,11 & $\mathbf{1 , 7}$ & 0,12 & $\mathbf{0 , 9}$ & 0,09 \\
los estudiantes que se estresan & & & & & & \\
Estoy muy cansado para disfrutar del curso & 2,7 & 0,12 & 2,6 & 0,13 & 2,2 & 0,12 \\
Rara vez me aburro en este curso & 2,3 & 0,12 & 2,2 & 0,11 & $\mathbf{1 , 9}$ & 0,11 \\
Mi alojamiento es agradable & 3,7 & 0,07 & 3,8 & 0,05 & 3,6 & 0,06 \\
Mi vida social es buena & 3,7 & 0,06 & 3,5 & 0,09 & 3,6 & 0,07 \\
Rara vez me siento solo & 3,3 & 0,09 & 3,2 & 0,12 & 3,2 & 0,12 \\
TOTALES & $\mathbf{1 4 1 , 4}$ & $\mathbf{1 , 5 4}$ & $\mathbf{1 4 1}$ & $\mathbf{1 , 9 0}$ & $\mathbf{1 2 1 , 3}$ & $\mathbf{2 , 1 6}$ \\
\hline
\end{tabular}


En general, la percepción del aprendizaje es calificada en un gran número de ítems con puntuaciones que se necesitan mejorar, especialmente en los de quinto curso, siendo para los de primero la sobreenfatización de hechos concretos y la centralización de la enseñanza en el profesor los dos hechos más llamativos, otros como la programación horaria o el desarrollo de la autoconfianza están muy próximos. Algo similar ocurre con los estudiantes de tercero, mientras que los de quinto, tienen percepciones de mayores problemas, los cuales constituyen una llamada urgente a la mejora.

Con respecto a la puntuación global debe indicarse que se mantiene, con una pequeña pérdida, en los de tercero y empeora significativa y drásticamente en los de quinto, en relación con los otros dos cursos, siendo la motivación, el desarrollo de la autoconfianza, el estímulo para ser un aprendedor activo, la idea sobre el enfoque de la enseñanza, el no estar centrada en el alumno, el énfasis sobre el corto más que sobre el largo plazo, etc., en fin, con excepción de la programación horaria, la claridad de los objetivos y la sobreenfatización de los hechos concretos en todos los demás ítems definidores de este constructo hay una pérdida significativa en los alumnos de quinto curso.

En la valoración de la enseñanza (profesorado) los alumnos en primero tienen claro que los profesores son autoritarios, se molestan en las clases y que los estudiantes les irritan (aspectos interesantes para incluir en el capítulo de la mejoría), los de tercero siguen considerando que son autoritarios y les molestan pero en menor medida y los de quinto vuelven a los niveles de los de primero en cuanto a que son autoritarios y aparecen además con caracteres alarmantes el hecho de que no facilitan retroalimentación, se siguen molestando en las clases, no favorecen la crítica constructiva y dudan de la habilidad en relacionarse con los pacientes.

En la valoración de la enseñanza, los alumnos de tercero mejoran con respecto a los de primero mientras que los de quinto decrecen significativamente con respecto a los cursos anteriores, siendo la falta de crítica constructiva, la relación con los pacientes y la falta de buen criterio en facilitar la retroalimentación los ítems con más claras pérdidas en puntuación. 
Respecto a las autopercepciones académicas las puntuaciones en general son bastante aceptables, siquiera también debe indicarse que los alumnos de quinto bajan la puntuación en los ítems correspondientes a: la consideración sobre si le están formando bien y sobre que mucho de lo que aprende duda que sea relevante para la Medicina, también duda sobre sus habilidades para resolver problemas y en que lo aprendido en el curso pasado haya sido una buena preparación para el actual.

Respecto a la atmósfera de aprendizaje que se «respira» en la facultad, las puntuaciones proporcionadas por los estudiantes, en general, son asimismo dignas de reseñar. Debe señalarse, sin embargo, que aquí la puntuación va decreciendo por cursos, menor la de tercero, todavía menor la de quinto. Los alumnos de quinto perciben que la Facultad no tiene los tiempos adecuadamente programados y dudan que el ambiente motive su aprendizaje; especialmente debe indicarse que equilibran la percepción en el ítem que se refiere a que el placer de estudiar medicina equilibra el estrés que el estudio le produce.

Finalmente, con respecto a la autopercepción social también se observa una progresiva disminución en el puntaje de primero a quinto. Los de primero no valoran el que haya un sistema de apoyo para los alumnos que se estresan e indican parcelas de aburrimiento; los de tercero coinciden con los de primero siendo más negativos todavía en la valoración del ítem relativo al estrés y los de quinto son notoriamente más negativos en ambos ítems a los que añaden el estar relativamente cansados para disfrutar del curso.

Para tener una apreciación global del puntaje se presenta la siguiente tabla, indicando el calificativo adecuado (Material y Métodos). 
TABLA 12.

Percepciones del medio ambiente de los estudiantes de Zaragoza

\begin{tabular}{|c|c|c|}
\hline $\begin{array}{l}\text { Medio ambiente } \\
\text { (Cursos) }\end{array}$ & Puntuación & Valoración \\
\hline \multicolumn{3}{|c|}{ Percepción del aprendizaje } \\
\hline $\begin{array}{l}\text { Primero } \\
\text { Tercero } \\
\text { Quinto }\end{array}$ & $\begin{array}{l}30.7 \\
29.8 \\
22.3\end{array}$ & $\begin{array}{l}\text { Valoración más positiva } \\
\text { id. } \\
\text { Consideración negativa }\end{array}$ \\
\hline \multicolumn{3}{|c|}{ Percepción de la enseñanza } \\
\hline $\begin{array}{l}\text { Primero } \\
\text { Tercero } \\
\text { Quinto }\end{array}$ & $\begin{array}{l}28.0 \\
30.3 \\
26.1\end{array}$ & $\begin{array}{c}\text { Dirección correcta } \\
\text { id. } \\
\text { id. }\end{array}$ \\
\hline \multicolumn{3}{|c|}{ Percepción académica } \\
\hline $\begin{array}{l}\text { Primero } \\
\text { Tercero } \\
\text { Quinto }\end{array}$ & $\begin{array}{l}23.5 \\
23.9 \\
20.8\end{array}$ & $\begin{array}{l}\text { Positivo - Confidente } \\
\text { id. } \\
\text { Positivo }\end{array}$ \\
\hline \multicolumn{3}{|c|}{ Percepción de la atmósfera } \\
\hline $\begin{array}{l}\text { Primero } \\
\text { Tercero } \\
\text { Quinto }\end{array}$ & $\begin{array}{l}37.6 \\
36.6 \\
33.2\end{array}$ & $\begin{array}{l}\text { Buena sensación de todo } \\
\text { id. } \\
\text { Positiva }\end{array}$ \\
\hline $\begin{array}{l}\text { Percepción socia } \\
\text { Primero } \\
\text { Tercero }\end{array}$ & $\begin{array}{l}21.5 \\
20.4\end{array}$ & $\begin{array}{l}\text { No demasiado malo/muy } \\
\text { bueno socialmente }\end{array}$ \\
\hline Quinto & 19.0 & id \\
\hline
\end{tabular}

\section{Discusión}

Los resultados obtenidos en la puntuación global (Zaragoza: 70.5.9 \% y Huesca: $61.2 \%$ respecto del total) están en línea con los obtenidos en otros contextos geográficos como UK: 66,2 \% (6), Tailandia: $68.7 \%$ (20), Nigeria: $59.0 \%(21)$ y Nepal: $65.0 \%$ (21) y mayores que los reportados para Trinidad: $55.0 \%$ (22), Canadá: $48.5 \%$ (19) y Arabia Saudita: 51.1 (23) y 45.0 (24).

Para los diferentes ambientes o subescalas exploradas con el DREEM: En la correspondiente a la percepción de los estudiantes del aprendizaje (Zaragoza $64.2 \%$ y Huesca $54.8 \%$-p<0.0001-), 
mientras que Zaragoza se halla en línea con los valores de UK (65.8 $\%)(6)$, Nigeria (68.8\%) (21) o Nepal (68.8\%) (21), Huesca se encontraría en los niveles de Trinidad (55.0\%) (22). El resto de facultades consultadas reportaron porcentajes más bajos en este ambiente. Respecto a los profesores, los valores de Zaragoza (62.2\%) están entre los valores más altos proporcionados por UK $(65.8 \%)(6)$ y Nigeria (59.1\%) (21) y Nepal (59.1\%) (21); Huesca (49.1\%, $\mathrm{p}<0.0001$ con relación a Zaragoza), en cambio, se ubicaría entre Canadá (54.5 \%) (19), Trinidad (53.6 \%) (22) y Arabia Saudita (48.3 y $45.5 \%)(23,24)$. En cuanto a la autopercepción del ambiente académico tanto los valores de Zaragoza (73.4\%) como los de Huesca $(70.6 \%, \mathrm{p}<0.01)$ se hallan incluso por encima de las entidades con mayores puntuaciones como son: UK (64.3\%) (6), Nigeria (65.6\%) (21) y Nepal (68.8\%) (21). Respecto a la autopercepción de los estudiantes de la atmósfera las puntuaciones de Zaragoza $(78.7 \%)$ y Huesca $(67.9 \%)(\mathrm{p}<0.0001)$ se encuentran, como en el caso anterior, entre o incluso por encima de las más elevadas: UK (68.6 \%) (6) y Nepal (66.7 \%) (21). Finalmente, las puntuaciones de los estudiantes de la autopercepción social proporcionan unos valores en Zaragoza $(76.8 \%)$ y Huesca $(68.6 \%)(0.01)$ están por encima de los valores del resto de entidades consultadas.

Los llamativos resultados de los alumnos de quinto curso podrían entreverse a raíz de la primera fotofija (25) de los alumnos de Medicina, respecto de los estilos de aprendizaje, que se ha presentado en el apartado anterior. Hace un cuarto de siglo se obtenía un hecho similar con los alumnos de sexto curso respecto a los de primero y tercero utilizando otro instrumento (26). Algunas de las peculiaridades podían preverse y son conocidas de los profesores como por ejemplo, la baja puntuación de los horarios en Huesca; otros, son más llamativos - el poco conocimiento, por ejemplo, de la existencia de un gabinete de psicología para entre otros el tratamiento del estrés-; todos deben abordarse y tratarse seriamente si se pretende una acción de mejora curricular. También se ha reportado en otros trabajos $(6,24)$ que las puntuaciones respecto a la enseñanza y al apoyo a los alumnos estresados son más altas en los alumnos de primer curso que en los alumnos que llevan más tiempo en la Facultad. En una Escuela de Enfermería de Tailandia (20) 
los estudiantes de primero proporcionaron calificaciones más altas que los de segundo y volvieron a subir en los de tercero y cuarto. El descenso se atribuyó a que los estudiantes de primero no tienen la experiencia suficiente para proporcionar una valoración válida de los procesos educativos. La observación de Till (19) que manifiesta que algunos estudiantes de primer curso proporcionan mensajes mezcla que pueden contribuir a las más bajas puntuaciones podría explicarnos el hecho de que los de tercero obtengan en alguna escala más alta puntuación que los de primero.

Por otra parte como indican Al-Ayed y Sheik (24) parece claro que los estudiantes pierden algo de la neutralidad que exhiben en el primer curso y llegan a ser más críticos con el medio ambiente educativo conforme ellos avanzan en sus estudios. Dicho de otra forma pierden algo del entusiasmo que manifestaban por su entrada en la Facultad de Medicina, lo que en nuestro medio significa tener unas notas que superan el 8 (sobre 10) en sus estudios. Sin embargo, los estudiantes de Nepal presentan valoraciones más altas en segundo y tercero que en primero (21).

En suma, el DREEM se revela como un instrumento de primera magnitud para detectar las deficiencias curriculares en los diferentes ambientes que analiza.

\section{Bibliografía}

1. Canfield, A. A. (1992). Canfield learning styles inventory (LSI) manual. Los Angeles: Western Psychological Services.

2. Escanero, J. F., Mora, S., Arce, J., Bianchi, A. R., Díaz Veliz, G., Gargiulo, P., Gorena, D., Lafuente, J. V., Landa, A. I., Terán, C. (2008). Estilos de aprendizaje (Facultades de Medicina). Zaragoza, Prensas Universitarias de Zaragoza.

3. Pace C.R., Stern G.G. (1958). An approach to the measurement of psychological characteristics of college environments. Journal of Educational Psychology, 49, 269-277.

4. Hutchins E. B. (1961). The 1960 medical school graduate: his perception of his faculty, peers and environment. Journal of Medical Education, 36, 322-329. 
5. Riquelme Pérez, A., Fuentes, G., Jeria, A., Méndez, I., Aranís, C., Larios, G., Oporto, J. Ambiente educacional y calidad de la docencia en la Escuela de Medicina. Ars Médica (Universidad Católica de Chile), vol 15, n. 15.

6. Roff, S., McAleer, S., Harden, R. M., Al-Qahtani, M., Uddin, A. A., Deza, H., Groenen, G., Primparyon, P. (1997). Development and Validation of the Dundee Ready Education Environment Measure (DREEM). Medical Teacher, 19(4), 295-299.

7. Rotem, A., Godwin, P., Du, J. (1995). Learning in Hospital Settings. Teaching and Learning in Medicine, 7(4), 211-217.

8. Roff, S., McAleer, S., Skinner, A. (2005). Development and Validation of an instrument to measure postgraduate clinical learning and teaching educational environment for hospital based junior doctors in the UK. Medical Teacher, 27(4), 326-331.

9. Casaar, K. (2004). Development of an instrument to measure three surgical operating theatre learning environment as perceived by basic surgical trainees. Medical Teacher, 26(3), 260264.

10. Holt, M., Roff, S. (2004). Development and validation of the Anaesthetic Trainee Theatre Educational Environment Measure (ATEEM). Medical Teacher, 26(6), 553-558.

11. Real Academia Española. (2001). Diccionario de la Lengua Española (22 $2^{\mathrm{a}}$ Ed.).

http: //buscon.rae.es/draeI/SrvltConsulta?TIPO_BUS=3\&LEMA $=$ clima

http://www.rae.es/

12. Whittle, S., Whelan, B., Murdoch-Eaton D.G. (2007). DREEM and beyond; studies of the educational environment as a jeans for its enhancement. Education for Health 20(1), 10-27.

13. Stenhouse, L. (1975). Introduction to Curriculum Research and Development. London, Heinemann.

14. Brady, L. (1990). Curriculum Development (3rd ed.). Sydney, Prentice Hall.

15. Genn, J. (2001). AMEE Medical Education Guide No 23 (Part 1): Curriculum, environment, climate, quality and change in medical education-a unifying perspective. Medical Teacher, 23(4), 337-344. 
16. Seabrook, M. A. (2004). Clinical students' initial reports of the educational climate in a single medical school. Medical Education, 38, 659-669.

17. Roff, S. (2005). The Dundee ready Educational Environment Measure (DREEM) - a generic instrument for measuring students' perceptions of undergraduate health professions curricula. Medical Teacher, 27(4), 322-325.

18. McAleer, S., Roff, S. (2002). Part 3: A practical guide to using the Dundee Ready Education Environment Measure (DREEM). AMEE Education Guide N. ${ }^{\circ}$ 23, Curriculum, environment, climate, quality and change in medical education: a unifying perspective, J.M. Genn (Ed.) (Dundee, U.K.: Association of Medical Education in Europe).

19. Till, H. (2004). Identifying the perceived weaknesses of a new curriculum by means of the Dundee Ready Education Environment Measure (DREEM) Inventory. Medical Teacher, 26(1), $39-45$.

20. Pimparyon, P., Roff, S., McAleer, S., Poonchai, B., Pemba, S. (2000). Educational environment, student approaches to learning and academic achievement in a Thai nursing school. Medical Teacher, 22(4), 359-364.

21. Roff, S., McAleer, S., Ifere, O. S., Bhattacharya, S. A. (2001). A global diagnostic tool for measuring educational environment: comparing Nigeria and Nepal. Medical Teacher, 23(4), 378-382.

22. Bassaw, B., Roff, S., MaAleer, S. Roopnarinesingh, S., Lisle, J. de, Teelucksingh, S., Gopaul, S. (2003). Students' perspectives on the educational environment, Faculty of Medical Sciences, Trinidad. Medical Teacher, 25(5), 522-526.

23. Al Hazmi, A., Al Hyiani, A., Roff, S. (2004). Perceptions of the educational environment of the medical school in King Abdul Aziz University, Saudi Arabia. Medical Teacher, 2004, 26(6), 570-3.

24. Al-Ayed, I. H., Sheik, S. A. (2008). Assessment of the educational environment at the College of Medicine of King Saud University, Riyadh. Eastern Mediterranean Health Journal, 14(4), 953-9.

25. Escanero, J. F., Puzo, J., Alda, J. O., Soteras, F. (1987). Estilos de aprendizaje de los estudiantes de las Facultades de Medicina 
(pregrado y postgrado). Universidad de Zaragoza, Instituto de Ciencias de la Educación. Informes, 22 (84 págs).

26. Schmeck, R. R., Ribich, F. D., Ramanaiah, N. (1979). Development of a self report inventory for assessing individual differences in learning processes. Applied Psychological Measurement, 1, 341-351, 1979. 


\section{ASSIST}

\section{Los enfoques de aprendizaje}

El marco teórico de los enfoques de aprendizaje fue desarrollado a partir de la investigación cualitativa de Marton y Säljö (1), quienes, desde una perspectiva fenomenológica, trataron de comprender los procesos de aprendizaje para evaluar las experiencias de aprendizaje de los estudiantes y la forma en que individualmente dan sentido a las tareas que se les encomiendan en las diferentes materias y cursos (2).

A partir de este enfoque teórico se desarrollaron diferentes líneas de investigación (3) dando lugar a diferentes escuelas dentro del marco de enfoques de aprendizaje. Entre ellos: el grupo de Entwistle, en Lancaster $(4,5)$, el grupo australiano de Biggs $(6,7)$, los suecos Marton y Säljö (1) y el grupo de Pask, en Richmond (8). Algunos de ellos, como los de Entwistle y Biggs, adoptaron metodologías cuantitativas dando como resultado inventarios e instrumentos que han sido frecuentemente utilizados en educación superior.

Con independencia de la escuela concreta, todas las investigaciones identificaban dos enfoques principales de aprendizaje: el superficial y el profundo. De esta forma, un estudiante que adopta un enfoque superficial adquiere los conocimientos necesarios para aprobar la materia, confía en la memorización y no trata de conectar los conceptos "aprendidos" con conocimientos previos o buscar las implicaciones. Es una concepción reproductiva del aprendizaje. Hall et al. (3) indican que el enfoque está orientado por motivaciones externas, fuertemente influenciado por los sistemas de evaluación y genera un grado de compromiso muy bajo con el material a aprender.

Por el contrario, el enfoque profundo viene definido por la existencia de un interés personal en aprendizaje. El estudiante busca el significado de lo aprendido y trata de conectar los nuevos conocimientos con los conceptos previos y con situaciones reales previas.

Swenson (citado por Salim -9-), en 1977, demostró que los estudiantes que adoptan un estilo profundo, emplean más tiempo en el 
estudio y consideran el material que aprenden como más fácil de comprender que los estudiantes que adoptan un estilo superficial. Estos últimos, al concentrarse en estrategias de memorización y retención, encuentran el trabajo pesado e ingrato y suelen fracasar más frecuentemente en los exámenes. También se ha analizado (10) que si la situación de aprendizaje está muy orientada al rendimiento y a la evaluación de resultados, los estudiantes pueden adoptar estilos superficiales que les conducen a intentar memorizar la información para superar las pruebas de evaluación o los exámenes.

En muchos aspectos, el enfoque profundo y superficial son equivalentes a los conceptos constructivistas de aprendizaje significativo y superficial, definidos por Ausubel (11).

Siguiendo a Arquero y Donoso (12), que a su vez habían adaptado de Hassall y Joyce (13), las características de ambos enfoques se pueden resumir como sigue:

TABLA 13.

Características asociadas a los enfoques

\begin{tabular}{ll}
\hline Enfoque profundo & Enfoque superficial \\
\hline $\begin{array}{l}\text { Deseo personal de comprender las } \\
\text { materias }\end{array}$ & $\begin{array}{l}\text { La simple reproducción de partes del } \\
\text { temario se considera suficiente }\end{array}$ \\
$\begin{array}{l}\text { Interacción fuerte y crítica con el } \\
\text { contenido }\end{array}$ & $\begin{array}{l}\text { Aceptación pasiva de las ideas y los } \\
\text { conceptos }\end{array}$ \\
$\begin{array}{l}\text { Se buscan relaciones con los } \\
\text { conocimientos y experiencias previas }\end{array}$ & $\begin{array}{l}\text { Los requisitos de los sistemas de } \\
\text { evaluación influyen fuertemente en el } \\
\text { aprendizaje }\end{array}$ \\
$\begin{array}{l}\text { Las ideas se integran usando } \\
\text { principios y conceptos organizadores }\end{array}$ & $\begin{array}{l}\text { No existen planes o estrategias de } \\
\text { aprendizaje }\end{array}$ \\
$\begin{array}{l}\text { Se buscan evidencias para llegar a } \\
\text { conclusiones }\end{array}$ & $\begin{array}{l}\text { Memorización de los hechos y los } \\
\text { procedimientos }\end{array}$ \\
Se evalúa la lógica de las & Incapacidad de reconocer los \\
conclusiones obtenidas & principios y conceptos básicos \\
& subyacentes \\
\hline
\end{tabular}

Además de los dos enfoques mencionados, se ha identificado un tercero denominado «enfoque de logro» $(14,15)$ que implica una intención claramente definida; obtener el máximo rendimiento posible a 
través de una planificación adecuada de las actividades, del esfuerzo y del tiempo disponible. Es decir, que este enfoque se caracteriza por la planificación y organización de las distintas actividades con el objetivo prioritario de obtener logros académicos lo más altos posibles (16).

Un hecho clave dentro del marco teórico de los enfoques de aprendizaje, como apunta Duff (17), es el que se refiere a la consideración de que dicho enfoque no se debe únicamente a las características personales de los estudiantes, sino que refleja, al menos en parte, una respuesta de cómo el estudiante percibe el contexto de aprendizaje (tanto el actual, como el pasado). A este respecto véase el modelo $3 \mathrm{P}$ de Biggs que hemos comentado en una publicación anterior (18).

\section{Del ASI (Approaches to Studying Inventory) al ASSIST}

Siguiendo a Duff (17), el inventario de enfoques de aprendizaje ASI de Entwistle et al. (19) es uno de los instrumentos más ampliamente usados en educación superior (20). El inventario original fue revisado en profundidad al comienzo de los 90 , quedando un cuestionario de 60 ítems, que proporcionaba cinco dimensiones: enfoques profundo, superficial, estratégico y apático, además de la actitud académica. Una versión reducida de 38 ítems (21) se desarrolló posteriormente, incluyendo cinco dimensiones: enfoque profundo, superficial y estratégico, la falta de dirección y confianza académica. La versión de 1995 (22) constaba de 44 ítems y añadió una sexta dimensión sobre la anterior versión: el conocimiento metacognitivo. Finalmente, la versión reducida del RASI de 1995, de 30 ítems, se centra en las tres dimensiones principales: enfoque profundo, superficial y estratégico (2).

La última versión del ASI es el Approaches and Study Skills Inventory for Students $(23,24)$. Es un instrumento de 52 ítems, que mide tres dimensiones o escalas principales: profundo, estratégico e instrumental (apático superficial). El enfoque estratégico (25) hace referencia al objetivo por parte de los estudiantes de obtener notas altas, usando el enfoque que consideren en cada caso más conveniente (profundo o superficial). Así, los estudiantes que siguen un enfoque estratégico trabajan eficazmente y con regularidad, organi- 
zan el tiempo y el esfuerzo para obtener los efectos máximos y verifican el progreso para asegurar el logro de los objetivos (26)

\section{Material y métodos}

\section{a) Muestra de estudio}

Se desarrolló un estudio transversal en el que se incluyeron 197 estudiantes de la Facultad de Medicina de la Universidad de Zaragoza pertenecientes a primero (69), tercero (64) y quinto (64) cursos. Los estudiantes que participaron en el estudio fueron los que un día, aleatoriamente elegido, estaban en clase.

\section{b) La herramienta}

Consta de tres apartados (A, B y C).

\section{Apartado A}

Las preguntas (seis) de este apartado pueden contemplarse como una jerarquía donde se atienden a dos referencias: unas apuntan a una aproximación instrumental del aprendizaje, que indican una concepción del aprendizaje como reproductor del conocimiento $y$, el resto, hacen referencia al aprendizaje implicando un conocimiento y desarrollo personales. Dos concepciones diferentes que se orientan al aprendizaje superficial y profundo, respectivamente En la aplicación de la herramienta esta primera sección o apartado podría ser omitida.

\section{Apartado B}

Las aproximaciones al estudio derivan también, como el apartado A, de las concepciones de Marton y Saljo (1). Consta de 52 ítems sobre las estrategias de aprendizaje. Las respuestas se clasifican de acuerdo con las tres aproximaciones al aprendizaje: profundo, superficial y estratégico o de logro. Las puntuaciones para estos tres principales enfoques se calculan a partir de la suma de las subescalas que contribuyen a cada uno de estos enfoques. Cada subescala está integrada por cuatro ítems. Por tanto, primero se determina el valor 
de las subescalas. Luego las subescalas que forman una aproximación al estudio (profundo, superficial y estratégica o de logro) se suman para obtener la puntuación en dicha aproximación. En la siguiente tabla se especifican estos conceptos.

TABLA 14.

Subescalas que forman cada aproximación

\begin{tabular}{lll}
\hline Aproximación profunda & Aproximación superficial & Aproximación estratégica \\
Búsqueda de significado & Falta de propósito & Estudio organizado \\
Relación de ideas & Memorizar sin relacionar & Gestión del tiempo \\
Uso de la evidencia & "Ley mínimo esfuerzo" & $\begin{array}{l}\text { Atención a las demandas de } \\
\text { las tareas }\end{array}$ \\
Interés en las ideas & Miedo al fracaso & Logros \\
& & Monitorización de la efectividad \\
\hline
\end{tabular}

Apartado C.

Trata de las preferencias por los diferentes cursos y enseñanzas.

Se evalúan en dos grupos de preguntas (ocho): unas (b, c, f, g) que se refieren al aprendizaje profundo y soportan o apoyan el conocimiento y otras (a, d, e, h,) que se refieren al aprendizaje superficial y van más con la transmisión de la información.

c) Valoración de los ítems

Los estudiantes responden a las preguntas en una escala del 1 al 5 (5 como valor máximo). Una salvedad únicamente. Cuando se valoran los ítems del aprendizaje profundo y superficial se debe tener en cuenta que las puntuaciones son positivas. Por tanto, cuanto mayor sea la puntuación superficial, tanto peor, ya que es más superficial.

\section{d) Estadística}

Los resultados se expresan como promedios \pm error estándar de las respuestas de los alumnos para cada ítem de los apartados A, B y C. Todas las comparaciones entre grupos se hicieron con la t de Student. 


\section{Resultados}

Apartado A: ¿Qué es aprendizaje?

Considerando a todos los estudiantes como un único grupo, en la tabla 3 se aprecia una leve, pero significativa, preferencia por el concepto de aprendizaje como reproductor del conocimiento (superficial). Al comparar los tres cursos, se aprecian estas leves diferencias que sólo son significativas en el 5. ${ }^{\circ}$ curso.

TABLA 15.

Preferencia por el tipo de concepto de aprendizaje

\begin{tabular}{lcccc}
\hline $\begin{array}{l}\text { Curso } \\
\text { (número estudiantes) }\end{array}$ & $\begin{array}{c}\mathbf{1 .}^{\circ} \\
(\mathbf{n}=69)\end{array}$ & $\begin{array}{c}\mathbf{3 .}^{\circ} \\
(\mathbf{n}=64)\end{array}$ & $\begin{array}{c}\mathbf{5 .}^{\circ} \\
(\mathbf{n}=64)\end{array}$ & $\begin{array}{c}\text { TODOS } \\
(\mathbf{n}=197)\end{array}$ \\
\hline Reproductor del Conocimiento & $11.7 \pm 0.2$ & $12.6 \pm 0.2$ & $11.8 \pm 0.3$ & $13.0 \pm 0.1$ \\
Conocimiento y Desarrollo Personal & $11.1 \pm 0.3$ & $12.2 \pm 0.3$ & $11.0 \pm 0.3^{\mathrm{a}}$ & $12.4 \pm 0.2^{\mathrm{a}}$ \\
\hline
\end{tabular}

aDiferencia significativa respecto a reproductor del conocimiento.

Apartado B: Aproximaciones al estudio

En la siguiente tabla se introducen los resultados obtenidos en los diferentes cursos analizados, así como una valoración global de los mismos. En ella, aparte de las tres aproximaciones al aprendizaje se indican los valores de los diferentes hábitos que integran cada uno de ellos.

TABLA 16.

Valores de las aproximaciones al aprendizaje y las respectivas subescalas

\begin{tabular}{lcccc}
\hline $\begin{array}{l}\text { Curso } \\
\text { (número estudiantes) }\end{array}$ & $\begin{array}{c}\mathbf{1 .}^{\circ} \\
(\mathbf{n}=69)\end{array}$ & $\begin{array}{c}\mathbf{3}^{\circ} \\
(\mathbf{n}=64)\end{array}$ & $\begin{array}{c}\mathbf{5 .}^{\circ} \\
(\mathbf{n}=64)\end{array}$ & $\begin{array}{c}\text { TODOS } \\
(\mathbf{n}=\mathbf{1 9 7})\end{array}$ \\
\hline APROXIMACION PROFUNDA & $76.5 \pm 1.4$ & $76.0 \pm 1.2$ & $78.0 \pm 1.3$ & $77.4 \pm 0.8$ \\
Búsqueda de significado & $15.5 \pm 0.3$ & $15.6 \pm 0.4$ & $16.3 \pm 0.3$ & $16.7 \pm 0.2$ \\
Relación de ideas & $14.7 \pm 0.4$ & $14.0 \pm 0.4$ & $14.6 \pm 0.3$ & $15.3 \pm 0.2^{\mathrm{e}}$ \\
Uso de evidencias & $15.5 \pm 0.3$ & $15.7 \pm 0.3$ & $15.9 \pm 0.3$ & $16.6 \pm 0.2$ \\
Interés en las ideas & $15.5 \pm 0.3$ & $15.5 \pm 0.4$ & $15.7 \pm 0.4$ & $16.5 \pm 0.2$ \\
\hline
\end{tabular}


TABLA 16. (continuación)

Valores de las aproximaciones al aprendizaje y las respectivas subescalas

\begin{tabular}{lcccc}
\hline $\begin{array}{l}\text { Curso } \\
\text { (número estudiantes) }\end{array}$ & $\begin{array}{c}\mathbf{1 .}^{\circ} \\
(\mathbf{n}=69)\end{array}$ & $\begin{array}{c}\mathbf{3 .}^{\circ} \\
(\mathbf{n}=64)\end{array}$ & $\begin{array}{c}\mathbf{5}^{\circ} \\
(\mathbf{n}=64)\end{array}$ & $\begin{array}{c}\text { TODOS } \\
(\mathbf{n}=197)\end{array}$ \\
\hline APROXIMACION ESTRATEGICA & $73.2 \pm 1.3^{\mathrm{a}}$ & $75.5 \pm 1.1$ & $77.1 \pm 1.4^{\mathrm{c}}$ & $75.8 \pm 0.7$ \\
Organización del estudio & $13.7 \pm 0.4$ & $14.8 \pm 0.4$ & $15.1 \pm 0.4$ & $15.4 \pm 0.2^{\mathrm{e}}$ \\
Gestión del tiempo & $14.5 \pm 0.4$ & $15.5 \pm 0.4$ & $16.3 \pm 0.4$ & $16.3 \pm 0.2$ \\
Atención demandas evaluación & $13.9 \pm 0.3$ & $13.5 \pm 0.3$ & $13.7 \pm 0.3$ & $14.6 \pm 0.2^{\mathrm{e}}$ \\
Logros & $15.3 \pm 0.4$ & $16.2 \pm 0.3$ & $16.0 \pm 0.4$ & $16.7 \pm 0.2$ \\
Control de la eficacia & $15.9 \pm 0.3$ & $15.6 \pm 0.3$ & $16.1 \pm 0.3$ & $16.8 \pm 0.2$ \\
APROXIMACION SUPERFICIAL & $61.0 \pm 1.4^{\mathrm{b}}$ & $54.4 \pm 1.5^{\mathrm{b}, \mathrm{d}}$ & $63.5 \pm 1.7^{\mathrm{b}}$ & $60.4 \pm 0.9^{\mathrm{b}}$ \\
Falta de propósito & $10.7 \pm 0.4$ & $8.2 \pm 0.4$ & $11.0 \pm 0.5$ & $10.9 \pm 0.3$ \\
Memorizar sin relacionar & $11.6 \pm 0.3$ & $10.5 \pm 0.6$ & $11.9 \pm 0.5$ & $12.3 \pm 0.3$ \\
Ley del menor esfuerzo & $11.9 \pm 0.4$ & $11.5 \pm 0.3$ & $12.8 \pm 0.5$ & $13.0 \pm 0.2$ \\
Miedo al fracaso & $14.6 \pm 0.5$ & $13.3 \pm 0.5$ & $15.1 \pm 0.5$ & $15.3 \pm 0.3^{\mathrm{e}}$ \\
\hline
\end{tabular}

a Diferencia significativa respecto a AP,

b Diferencia significativa respecto a AP y AE,

c Diferencia significativa respecto al AE del $1 .^{\text {er }}$ año,

${ }^{d}$ Diferencia significativa respecto al AS de $1 .^{\text {er }}$ y $5 .^{\circ}$ año,

e Diferencia significativa respecto a las otras subescalas de la misma aproximación.

Al comparar los totales de los puntajes obtenidos por todos los estudiantes en cada una de la aproximaciones (profunda, estratégica y superficial) se observa que predominan las aproximaciones profunda y estratégica sobre la superficial.

No hay diferencias significativas entre las aproximaciones profunda y estratégica comparando todos los estudiantes; sin embargo, si que se han encontrado en el primer año donde es mayor el enfoque profundo que el estratégico. Llama la atención que a medida que avanzan en sus estudios los estudiantes se van volviendo mas estratégicos (en $5 .^{\circ}$ año son significativamente mas estratégicos que en $1 .^{\circ}$ año).

De lo anterior se desprende que el aprendizaje superficial es la menos preferida de las aproximaciones al estudio. Esto pasa en los tres cursos. También es sorprendente que en $3 .^{\circ}$ año los estudiantes parecen ser menos superficiales que en $1 .^{\circ}$ y $5 .^{\circ}$ año. 


\section{Hábitos de estudio}

$\mathrm{Al}$ analizar los hábitos preferentes que caracterizan cada una de las tres aproximaciones, estadísticamente se aprecia lo siguiente:

- Aprendizaje profundo: El hábito menos preferido es la «relación de ideas».

- Aprendizaje estratégico: Los hábitos mayoritarios son «el control de la eficacia», «los logros» y «la gestión del tiempo», en ese orden.

- Aprendizaje superficial: El factor de mayor peso para determinar este tipo de aprendizaje es con mucho «el miedo al fracaso», seguido a cierta distancia por la «ley del menor esfuerzo», «la memorización sin sentido»y, finalmente, «la falta de propósito».

Apartado C: Preferencias por diferentes tipos de curso y enseñanza

No se apreciaron diferencias significativas entre las preferencias por aprendizaje profundo o superficial, en el total de estudiantes o separados por cursos.

\section{Discusión}

Cuando se habla sobre los enfoques de aprendizaje definidos por Entwistle (15), no deben quedar dudas respecto a promover el enfoque profundo en los estudiantes universitarios. Es decir, la teoría de los enfoques de aprendizaje no es ajena a la identificación de uno de ellos como el deseable y el otro como el no deseable. En cierto sentido, mediante el ASSIST se identifica el enfoque de un estudiante pero a la vez se promueve el fortalecimiento de uno de ellos y el debilitamiento del otro. Aunque puede llegar a servir para clasificar a los estudiantes, la intención primordial es ubicarlos dentro de un punto en su desarrollo profesional y tratar de llevarlo hacia un punto superior. Trabajar en su formación para motivar en él un sentido de interés en las ideas y un aprendizaje significativo (27).

Los estudiantes de la Facultad de Medicina de Zaragoza manifiestan que el enfoque profundo es el más adoptado para abordar el 
aprendizaje de las distintas materias de los cursos explorados. Por orden de importancia, la segunda opción es el enfoque estratégico, quedando el superficial como tercera alternativa. Dos hechos llaman la atención: el primero se refiere al incremento de la aproximación estratégica de los estudiantes de quinto curso y el segundo al descenso del enfoque superficial en los de tercero.

Los resultados de otras instituciones son dispares. Así, en la Universidad Austral de Chile, alumnos de cuatro áreas de estudio (Humanista, Biológica, Comercial y Tecnológica) manifestaron adoptar como primera opción la aproximación estratégica, seguida de la profunda, siendo la superficial la alternativa señalada en menor proporción (27). En cambio, los alumnos de Bioquímica de Tucumán (Argentina) a los que se les aplicó el Cuestionario de Evaluación de Procesos de Estudio y Aprendizaje (CEPEA) para el alumnado universitario, los alumnos que aplicaban el enfoque profundo era superior a la suma de los otros dos (28). En Murcia, los estudiantes de varias licenciaturas de letras (Pedagogía, Psicopedagogía, Informática e Historia) globalmente considerados tienen un enfoque de aprendizaje profundo $(47,50 \%)$ y un enfoque superficial $(42,22 \%)$, mayoritariamente. Solamente el 10,28 \% tienen un enfoque de alto rendimiento o de logro. Por titulaciones, los estudiantes de Pedagogía $(57,65 \%)$ y los de Informática $(59,57 \%)$ manifiestan preferir un enfoque superficial, mientras que los estudiantes de Psicopedagogía $(51,16 \%)$ y los de Historia $(66,67 \%)$ prefieren un enfoque de aprendizaje profundo (29). Los resultados realizados en estudiantes de la Universidad de La Coruña, pertenecientes a Magisterio, Enfermería, Fisioterapia, Ciencias Empresariales, Psicopedagogía, y Ciencias Químicas, reflejan la existencia de tres clusters: el cluster 1, integrado por aquellos estudiantes con una escasa utilización de ambos enfoques de aprendizaje; el cluster 2 , formado por estudiantes con predominio de un enfoque profundo; y el cluster 3 formado por estudiantes con predominio de un enfoque superficial (30). Por otra parte, en el mundo anglosajón los resultados son bastante parecidos (27), como podrá verse más abajo, al analizar los factores determinantes de los enfoques.

De acuerdo con Entwistle (15), el enfoque de aprendizaje no debería considerarse como una característica estable del estudiante, sino 
como la forma de enfrentar el estudio. Los contenidos y el ambiente de estudio lo pueden afectar en diferentes grados y llevar al estudiante a adoptar y desarrollar diferentes enfoques. Cuando ingresan a la educación superior, tienen creencias más o menos firmes de lo que significa aprender. Dichas creencias proceden de las experiencias previas del sistema educativo. Es posible que en el primer año los estudiantes tengan la intención de adquirir un enfoque profundo, pero pronto se dan cuenta que les consume mucho tiempo.

Por lo regular, a lo largo de la carrera, los estudiantes están sometidos a una carga fuerte de estudios, en cuanto a la cantidad de materias o contenidos diferentes que tienen que procesar simultáneamente. Se enfrentan, entonces, a una problemática generada desde el entorno curricular. Están cambiando constantemente de actividad, de una materia a otra, tratando de cumplir con todas ellas. Podría ser que esto afectara negativamente al proceso de aprendizaje, debido a que no le dedican el tiempo suficiente para reflexionar, teorizar y aplicar ideas. Esto explicaría por qué el estudiante se va haciendo cada vez más estratégico, sin descartar el recurrir a enfoques superficiales de acuerdo a las tareas de aprendizaje que se le demanden. Es probable que los alumnos de tercero experimenten alguna influencia motivadora que hace que el enfoque superficial sea el menos representativo y podría ser el cambio temático que experimentan en tercero: abandono de las básicas e introducción al mundo médico (Patología General, Propedeútica Principios Quirúrgicos, etc). Otro factor que también puede comenzar a aflorar en este curso es la necesidad de contar con una buena puntuación para poder elegir especialidad en la prueba MIR.

Salas (27), para justificar el alto enfoque estratégico en los estudiantes chilenos indica que su principal objetivo, durante su paso por la universidad, es lograr un título académico. Y entre sus estrategias de aprendizaje ocupa un lugar preponderante el aprendizaje memorístico. Sin embargo, al mismo tiempo, los estudiantes manifiestan una serie de factores/hechos positivos, como: estar motivados no tanto por el miedo al fracaso como por la esperanza de éxito, echan mano de la evidencia y de la lógica y otra serie de características relevantes (son organizados, controladores del tiempo y poniendo mucho esfuerzo en su estudio). 
Por otra parte, las variables contribuyentes al enfoque estratégico, asociado siempre a un aprendizaje memorístico, en los estudiantes de la Universidad Austral de Chile no concuerdan con los resultados de las investigaciones efectuadas en Inglaterra (19, 25, 31), en Bélgica (32) o en la propia Chile (La Serena) (33), en donde el enfoque estratégico aparece siempre asociado con un enfoque en profundidad. Sin embargo, Biggs (34) sostiene que el aprendizaje de memoria no significa que el estudiante esté adoptando un enfoque superficial. Así, por ejemplo, el recuerdo acucioso de una información ya comprendida puede implicar un aprendizaje memorístico, pero eso no quiere decir que sea un enfoque superficial, sino parte de un enfoque profundo o estratégico y Sadler-Smith y Tsang (35) afirman que en las culturas asiáticas la comprensión puede llegar a través de la memorización. Según Biggs (34), en Hong Kong llaman a ese enfoque «memorización profunda». Watkins, Reghi y Astilla (36) lo explican diciendo que la división importante no está entre memorización y comprensión (enfoques superficial y profundo en la terminología occidental), sino entre una memorización mecánica y una memorización con comprensión. Por lo tanto, memorización y comprensión no serían antitéticas, sino que serían dos estrategias de aprendizaje que expresan sólo diferencias cualitativas y, por lo tanto, no excluyentes. Por lo demás, Kember y Leung (37) concluyen en su estudio que la dimensión de logro/estratégica no es una tercera categoría de constructo de enfoque de aprendizaje, sino que, más bien, representa una dimensión adicional que puede ser presentada tanto junto con la orientación de significado (enfoque profundo) como con la de reproducción (enfoque superficial).

Los comentarios anteriores y los resultados discutidos vendrían a ratificar lo que Harper y Kember (38) habían detectado hace ya unos años y es que los factores pueden tener significados claramente diferentes según la facultad, porque hay en ellos un elemento de influencia ambiental considerable.

Finalmente, a pesar de que creamos que los estudiantes que adoptan el enfoque profundo combinado con el estratégico, como sucede en la Universidad de Zaragoza, son mejores para discernir y utilizar eficientemente los aspectos del ambiente de aprendizaje que apoyen su manera de estudiar, no tenemos duda de que es necesario 
crear un ambiente que estimule el desarrollo de un enfoque profundo, como hemos iniciado esta Discusión: aunque la teoría de los enfoques puede llegar a servir para clasificar a los estudiantes, la intención primordial es ubicarlos dentro de un punto en su desarrollo profesional y tratar de llevarlo hacia un punto superior. Trabajar en su formación para motivar en él un sentido de interés en las ideas y un aprendizaje significativo.

Esto implica intervenir en el contexto general del aprendizaje. En otras palabras, hay que considerar el currículum, los métodos de enseñanza, la evaluación, las experiencias previas de los estudiantes y sus percepciones del aprendizaje. Un hecho orientador lo puede constituir el trabajo de Speth et al. (39) que recomiendan la utilización del aprendizaje online para los enfoques superficiales ya que evita el nerviosismo y otras peculiaridades propias de los alumnos con este enfoque.

\section{Bibliografía}

1. Marton, F., Säljö, R. (1976). On qualitative differences in learning. Outcome and process. British Journal of Educational Psychology, 46, 4-11.

2. Duff, A. (1999). Access policy and approaches to learning. Accounting Education. An International Journal. 8, 2, 99-110.

3. Hall, M., Ramsay, A., Raven, J. (2004). Changing the learning environment to promote deep learning approaches in first-year accounting students. Accounting Education, 13, 4, 489-505.

4. Entwistle, N. J., Wilson, J. D. (1970). Personality, study methods and academic performance. University Quarterly, 21, 147-46.

5. Entwistle, N. J., Thompson, J. B., Wilson, J. D. (1974). Motivation and study habits. Higher Education, 3, 4, 379-96.

6. Biggs, J. B. (1978). Individual and group differences in study process, British Journal of Educational Psychology, 48, 3, 26679 .

7. Biggs, J. B. (1987). Student Approaches to Learning and Studying. Hawthorn: Australian Council for Educational Research.

8. Pask, G. (1976). Styles and strategies of learning. British Journal of Educational Psychology, 46, 2, 128-48. 
9. Salim, R. El cuestionario Cepea: Herramienta de evaluación de enfoques de aprendizaje de estudiantes universitarios. IV Encuentro Nacional y I Latinoamericano 'La Universidad como Objeto de Investigación' - Tucumán, R. Argentina - Octubre 2004. Revista Iberoamericana de Educación (ISSN: 16815653).

10. Fransson, A. (1977). On qualitative differences in learning IV. Effects of motivation and test anxiety on process and outcome. British Journal of Educational Psychology, 47, 244-257.

11. Ausubel, D. P. (1968). Educational psychology: a cognitive view. Holt, Rinehart and Winston.

12. Arquero, J. Donoso, J. A. (2008). Conociendo a nuestros estudiantes de contabilidad. Sus estilos y enfoques de aprendizaje. I Congreso Internacional sobre Profesorado Principiante e Inserción Profesional a la Docencia. Sevilla, Facultad Ciencias de la Educación, junio.

13. Hassall, T., Joyce, J. (2001). Approaches to learning of management accounting students. Education + Training. 43, 3, 145-152.

14. Biggs, J. B. (1984). Learning strategies, student motivation patterns and subjectively perceived success. En J. R. Kirby (Ed.). cognitive strategies and educational performance (p. 111-134). Orlando (Florida), Acad. Press.

15. Entwistle, N. J. (1988). Motivational factors in student's approaches to learning. En: R. R. Schmeck (Ed.), Learning strategies and learning styles. Nueva York, Plenum Press.

16. Valle Arias, A., Barca, A., González Cabanach, R., Porto Rioboo, A., Santorum, R. (1993). Aprendizaje significativo y enfoques de aprendizaje: El papel del alumno en el proceso de construcción de conocimientos. Revista de Ciencias de la Educación, 156, 481-502.

17. Duff, A. (2004a). The revised approaches to studying inventory and its use in management education. Active learning in higher education. 5, 1, 56-72.

18. Escanero, J. F., Soria, M. S., Lafuente, J. V., Ezquerra, L. (2007). Formular y evaluar competencias. Universidad de Zaragoza, Prensas Universitarias de Zaragoza. Guía, 4, 179 págs.

19. Entwistle, N., Hanley, M., Hounsell, D. (1979). Identifying distinctive approaches to studying. Higher Education, 8, 365-380. 
20. Duff, A. (2004b). Understanding academic performance and progression of first-year accounting and business economics undergraduates: the role of approaches to learning and prior academic achievement. Accounting Education. An International Journal, 13, 4, 409-430.

21. Entwistle, N. J., Entwistle, A. (1991). Contrasting forms of understanding for degree examinations: the students experience and its implications. Higher Education, 205, 227.

22. Tait, H., Entwistle, N. J. (1995). Revised Approaches to Studying Inventory 1995. Edinburgh, Centre for Learning and Instruction, University of Edinburgh.

23. ASSIST (1997) Approaches and Study Skills Inventory for Students. Edinburgh, Centre for Research on Learning and Instruction, University of Edinburgh.

24. Tait, H., Entwistle, N. J., McCune, V. (1998). ASSIST: a reconceptualisation of the approaches to studying inventory, in: Rust, C. (Ed.) Improving Student Learning: Improving Students as Learners. Oxford, The Oxford Centre for Staff and Learning Development.

25. Entwistle, N. J., Ramsden, P. (1983). Understanding student learning. London, Croom Helm.

26. Byrne, M., Flood, B., Willis, P. (2002). Approaches to learning of European business students. Journal of Further and Higher Education, 21-1, 19-28.

27. Salas, R.versión On-line ISSN 0718-0705.

28. Salim, S. R. (2006). Motivaciones, enfoques y estrategias de aprendizaje en estudiantes de Bioquímica de una universidad pública argentina. Revista Electrónica de Investigación Educativa (REDIE), 8, 1.

29. Hernández Pina, F., Hervás Avilés, R. M. (2004). Enfoques y estilos de aprendizaje en Educación Superior. I Congreso Internacional de Estilos de Aprendizaje. UNED de Madrid, Madrid, julio. tecnologiaedu.us.es/estilosdeaprendizaje/Comunicaciones/ EE\%20AA\%20Ed.\%20Universitaria/Hernandez-Hervas.doc.

30. Valle Arias, A., González Cabanach, R., Núñez Pérez, J. C., Suárez Riveiro, J. M., Piñeiro Aguín, I., Rodríguez Martínez, S. (2000). Enfoques de aprendizaje en estudiantes universitarios. Psicothema, 12(3), 368-375. 
31. Ramsden, P., Entwistle, N. J. (1981). Effects of academic departments on students' approaches to studying. British Journal of Educational Psychology 51: 368-383.

32. Zuñiga, M. (1989). La performance académique, impact des approaches déclarées, de la perception du contexte et des attributions causales de la réussite. Analyse quantitative et qualitative. (Tesis doctoral). Bélgica: Université Catholique Louvain.

33. Zuñiga, M. (1994). Enfoques de aprendizaje en contextos académicos naturales: una perspectiva comparativa. $2^{\circ}$ Encuentro Nacional de Enfoques Cognitivos Actuales en Educación, pp. 168-178. Stgo.: Pontificia Universidad Católica de Chile, Fac. de Educación.

34. Biggs, J. (1993). What do inventories of students' learning processes really measure? A theorical review and clarification. British Journal of Educational Psychology 63: 3-19.

35. Sadler-Smith, E. y Tsang, F. 1998. A comparative study of approaches to studying in Hong Kong and the United Kingdom. British Journal of Educational Psychology 68: 81-93.

36. Watkins, D., Hattie, J. y Astilla, E. (1986). Approaches to studying by filipino students: A longitudinal investigation. British Journal of Educational Psychology 56: 357-362.

37. Kember, D., Leung, D. (1998). The dimensionality of approaches to learning: an investigation with confirmatory factor analysis on the structure of the SPQ and LPQ. British Journal of Educational Psychology 68: 395-407.

38. Harper, G., Kember, D. (1989). Interpretation of factor analyses from the approaches to studying inventory. British Journal of Educational Psychology 59: 66-74.

39. Speth, C., Lee, D., Hain, P. Get an ASSIST and support your students' learning online. www.uwex.edu/disted/conference/ Resource_library/handouts/03Info_H21.pdf. 


\section{CHAEA ${ }^{1}$}

\section{Antecedentes}

Basándose en el Learning Style Inventory de Kolb (LSI), Honey y Munford desarrollaron el Learning Style Questionnaire (LSQ) (1), que posteriormente fue adaptado al contexto académico español por Alonso, Gallego y Honey con el nombre de CHAEA (2). Estos autores realizaron un análisis con un mayor número de variables y concluyeron que los estilos de aprendizaje podrían agruparse en cuatro tipos: Activo, Reflexivo, Teórico y Pragmático, que se podrían asimilar a las fases del ciclo de aprendizaje de Kolb. La Teoría del Aprendizaje Experiencial del mencionado autor (3) señala que el aprendizaje es el proceso por el cual se crea conocimiento a través de la transformación de la información o experiencia. Así, el conocimiento resultaría de la combinación de obtención y transformación de la información. De esta forma, la teoría establece dos modos dialécticamente relacionados para obtener información, la experiencia concreta y la conceptualización abstracta, y otros dos también dialécticamente relacionados para transformar la información, la observación reflexiva y la experimentación activa. El proceso es idealizado como un ciclo o espiral de aprendizaje, donde el aprendedor pasa por las fases de experimentación, reflexión, pensamiento y acción, que responde a la situación de aprendizaje y a lo que está siendo aprendido (4). Estas cuatro fases sirven para determinar los cuatro estilos de Honey-Alonso.

A continuación se describen las principales características de cada uno de ellos:

Activo: personas que se caracterizan por buscar nuevas experiencias. Son de mente abierta, muy activos, comprometidos con el trabajo del grupo y se involucran con entusiasmo en nuevas tareas.

Reflexivo: personas observadoras y que consideran las experiencias desde diferentes ángulos. Analizan con cuidado antes de llegar a una conclusión y su filosofía es ser prudentes.

1 Los resultados presentados con este instrumento forman parte de un trabajo que aparecerá en Educ. Med. en un próximo número. 
Teórico: personas que buscan la racionalidad y la objetividad, huyendo de todo lo que es ambiguo y subjetivo. Predomina el pensamiento lógico, el ser perfeccionista y la integración de los conceptos en teorías lógicas.

Pragmático: personas en las que predomina la aplicación práctica de las ideas. Les gusta actuar con seguridad y experimentar el aspecto positivo de las nuevas ideas.

\section{Material y métodos}

\section{a) Muestra de estudio}

Este estudio se realizó en 164 estudiantes de las Facultades de Medicina de las Universidades del País Vasco y Zaragoza, con objeto de determinar los estilos de aprendizaje de los estudiantes, en unos momentos en que se está procediendo a un cambio curricular importarte.

\section{b) Instrumento utilizado}

Los estilos de aprendizaje se determinaron aplicando el Cuestionario Honey-Alonso de Estilos de Aprendizaje (CHAEA) (2), que valora la preferencia por cada uno de los siguientes cuatro estilos de aprendizaje: activo, reflexivo, teórico y pragmático. El cuestionario consta de 80 ítems, breves y dicotómicos, de los cuales 20 corresponden a cada estilo de aprendizaje y están distribuidos aleatoriamente. La puntuación absoluta que se obtiene en cada grupo de 20 ítems indica el nivel que alcanza el individuo en cada uno de los cuatro estilos. La representación sobre un eje cartesiano permite determinar cada estilo preferente.

\section{c) Conversión al Modelo de Kolb}

Los estilos de Alonso, Gallego y Honey (1) pueden convertirse en los estilos de aprendizaje de Kolb $(5,6)$. En la siguiente tabla abierta se indica la equivalencia de estilos de aprendizaje entre ambos modelos: 
TABLA 17.

Equivalencia de los estilos de aprendizaje entre CHAEA y Kolb

\begin{tabular}{ll}
\hline CHAEA de Alonso-Gallego- Honey & LSI de Kolb \\
\hline Activo & Experiencia Concreta (EC) \\
Reflexivo & Observación Reflexiva (OR) \\
Teórico & Conceptualización Abstracta (CA) \\
Pragmático & Experimentación Activa (EA) \\
\hline
\end{tabular}

Los valores de $x$ e $y$ necesarios para su representación se obtuvieron con la diferencia neta entre los puntajes del cuestionario Honey-Alonso para cada par de estilos antagónicos (teórico versus activo, y pragmático versus reflexivo). La cuenta final del número de estudiantes adjudicados a cada cuadrante determinó el porcentaje para cada estilo.

\section{d) Tratamiento estadístico}

Para procesar la información de los cuestionarios se elaboró una base de datos en el programa Excel y se realizó un análisis estadístico con el programa GraphPad Prism versión 5. Dicho análisis consistió en la comparación de las puntuaciones medias obtenidas en los cuatro estilos de aprendizaje, según Honey-Alonso, en los diferentes cursos de las Universidades involucradas en el estudio. Posteriormente, se transformaron los datos para obtener las puntuaciones de acuerdo al modelo de Kolb como fue señalado anteriormente. Se aplicó el análisis de varianza de una vía (ANOVA) para cada estilo, seguido por la prueba de Bonferroni para comparaciones múltiples, teniendo en cuenta la homogeneidad de las varianzas. La comparación de los porcentajes se realizó con la prueba de $c h i^{2}$. En cada caso se consideró como significativo una $\mathrm{p}<0,05$.

\section{Resultados}

En la Figura 5, al comparar los estilos de aprendizaje preferentes de los estudiantes de Zaragoza y del País Vasco se observa un comportamiento similar con un puntaje significativamente inferior 
en todos los casos $(\mathrm{p}<0.001)$ en los estudiantes de esta última facultad. El estilo de mayor preferencia fue el reflexivo seguido del teórico en cada una de las facultades, significativamente $(\mathrm{p}<0.001)$ más elevados que los otros dos. En la Facultad de Medicina de Zaragoza la tercera posición la ocupó el pragmático con diferencias significativas $(\mathrm{p}<0.001)$ con respecto al activo.

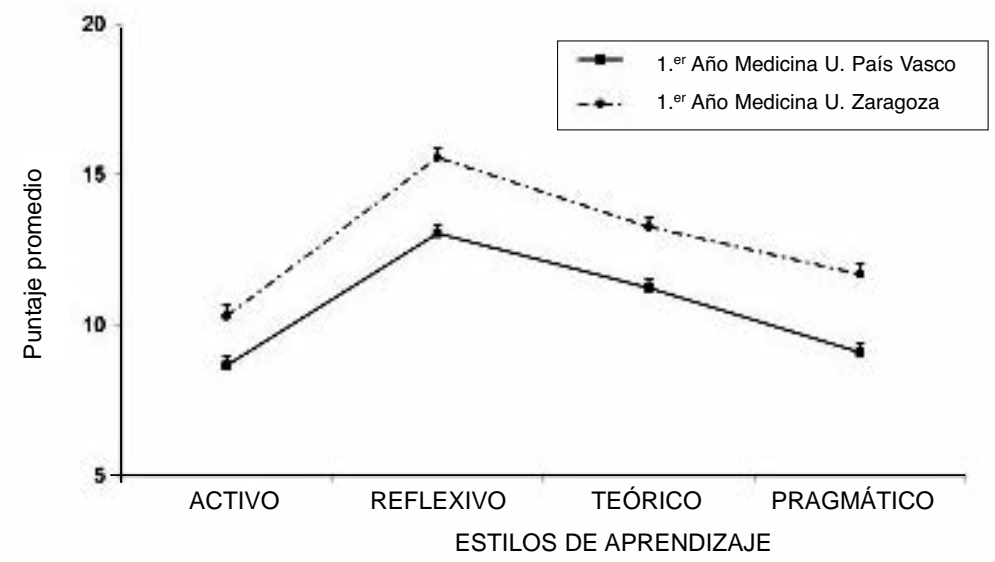

Figura 5. Estilos de aprendizaje: Puntaje promedio obtenidos para cada estilo de aprendizaje en estudiantes de primer año de las Facultades de Medicina de las universidades indicadas.

$\mathrm{Al}$ combinar las preferencias en la adquisición y procesamiento de la información y confeccionar el gráfico de dispersión con la ubicación de cada estudiante dentro de su estilo de aprendizaje preponderante (Kolb), se observa que los estudiantes se concentran significativamente en el estilo asimilador (65 y $62 \%$, respectivamente). (Figura 6).

\section{Discusión}

En la última década se han realizado importantes esfuerzos por conceptualizar las características de los estilos de aprendizaje de los estudiantes universitarios de Ciencias de la Salud (7, 8, 9, 10, 11, 12). Los resultados obtenidos en esta investigación indican que los estudiantes de Medicina tienen preferencia por los estilos reflexivo 


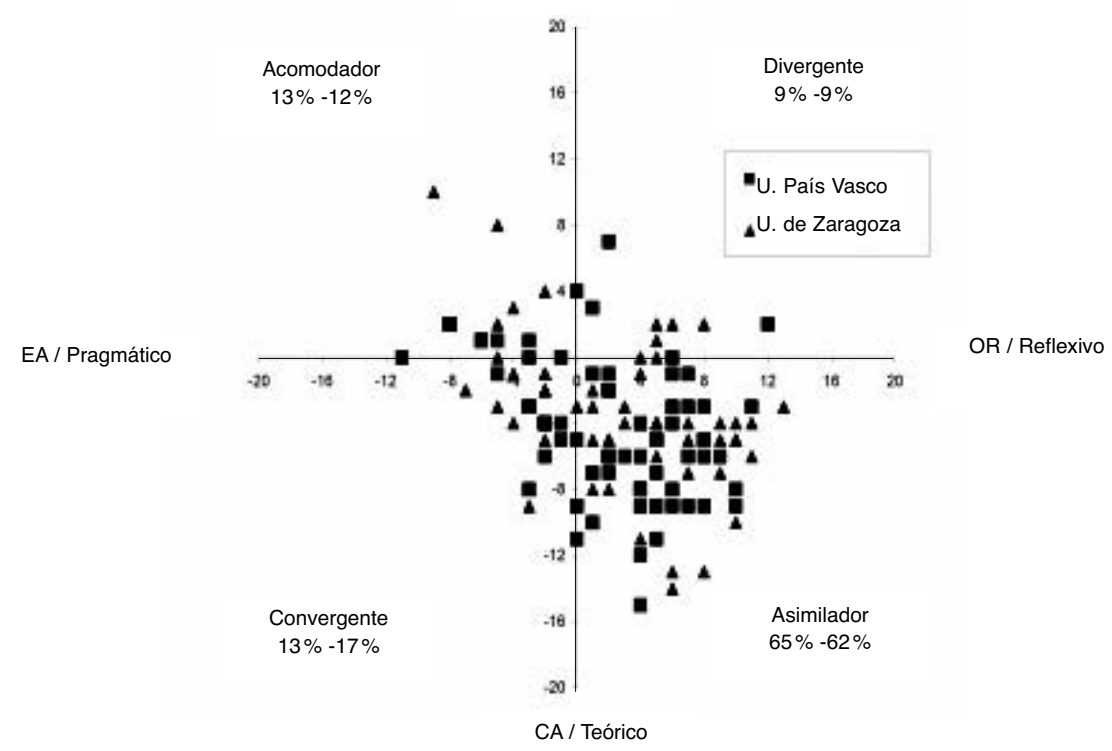

Figura 6. Estilos de aprendizaje: Diagrama de dispersión con el estilo preponderante de cada estudiante de primer curso de las Facultades de Medicina de las Universidades del País Vasco (España) y de Zaragoza. Los ejes indican estilos según Kolb/Honey-Alonso. Los porcentajes señalan la proporción de individuos en cada cuadrante (perfil de preferencias individuales).

y teórico, los que muestran bastante estabilidad a lo largo de su formación académica. Otras investigaciones realizadas en estudiantes de Medicina de la Universidad de Zaragoza (10) y estudios transversales llevados a cabo en estudiantes de Ciencias de la Salud de la Universidad de Cádiz (11) y de la Escuela Universitaria de Enfermería La Paz de Madrid (12) también han mostrado una tendencia hacia un estilo de aprendizaje reflexivo y teórico.

Se podría especular que la mayoría de los estudiantes de Ciencias de la Salud posee un perfil de aprendizaje que los diferencia, por ejemplo, de los estudiantes de Bellas Artes o Filosofía (2). Es muy probable que este perfil se haya forjado antes del ingreso a la Universidad, posiblemente durante la enseñanza secundaria, el cual no cambia a medida que los estudiantes avanzan en su formación, de 
acuerdo con los resultados obtenidos en los 3 cursos de la Universidad de Chile (13). Más aún, es probable que las estrategias didácticas utilizadas por los docentes, favorezcan el aprendizaje y rendimiento de los estudiantes con estilos reflexivos y teóricos, potenciando así las preferencias de los estudiantes por dichos estilos.

Los estilos de aprendizaje, según Kolb, pusieron de manifiesto que los estudiantes de las dos universidades españolas son preferentemente asimiladores, característica que ya había sido señalada por otros autores $(3,7)$ y, en concreto, para Zaragoza (7). Estos estudiantes utilizan la conceptualización abstracta y la observación reflexiva, siendo capaces de percibir gran cantidad de información y procesarla en forma lógica.

El tener preferencia por uno o dos estilos de aprendizaje no es ni malo ni bueno intrínsecamente. Más aún, es probable que la mayoría de estudiantes de medicina privilegie aquel o aquellos estilos que les han permitido tener éxito en su formación académica y que no estén dispuestos a cambiarlos en forma espontánea. El ideal sería que los aprendedores desarrollaran en forma equilibrada todas sus capacidades para conseguir un aprendizaje significativo, ya que las situaciones a las que se enfrentarán en su formación futura requerirán de diferentes estrategias de aprendizaje (2). Por lo tanto, sería un deber de las Facultades de Medicina buscar alternativas metodológicas para potenciar el desarrollo de los estilos activos y pragmáticos, en la misma medida que los estilos reflexivos y teóricos. El estudiante más capacitado será aquel capaz de aprender en cualquier situación, ya que aprovechará mejor las oportunidades de aprendizaje que se le presenten a lo largo de su vida. Afortunadamente las preferencias por determinados estilos de aprendizaje no son inmutables. Según Alonso (2), ellos evolucionan de acuerdo con nuestra edad cronológica y nuestras experiencias. Podemos mejorar cada uno de los estilos a través de la metacognición y prácticas docentes adecuadas que permitan reforzar nuestros estilos preferentes y potenciar nuestros estilos menos desarrollados $(6,7)$. Los profesores deben ser capaces de utilizar distintos estilos de enseñanza para facilitar el aprendizaje de alumnos con distintos estilos de aprendizaje y fomentar la flexibilidad de los alumnos en el uso de los diferentes estilos. 


\section{Bibliografía}

1. Honey, P., Munford, A. (1986). The Manual of Learning Styles. Maidenhead (Berkshire), P. Honey, Ardingly House.

2. Alonso, C., Gallego, D., Money, P. (1994). Los estilos de aprendizaje. Procedimientos de diagnóstico y mejora. Bilbao, Mensajero.

3. Kolb, D. A. (1984). Experiential Learning: Experience as the Source of Learning and Development. Englewood Cliffs (New Jersey), Prentice Hall.

4. Kolb, A. Y., Kolb, D. A. (2005). Learning styles and learning spaces: Enhancing experiential learning in higher education. Academy of Management Learning and Education, 4(2), 193-212.

5. Kolb, D. A. (1976). The Learning Style Inventory: Technical Manual. Boston, McBer.

6. Kolb, D. A. (1999). Learning Style Inventory, Version 3. Technical specifications. Boston, MA: TRG Hay/McBer Training Resources Group.

7. Escanero, J. F., González-Haro, C., Ezquerra, L., Borque, L. (2009). Diseño e implementación de una práctica de metacognición en la asignatura de Fisiología Humana (Facultad de Medicina). Educación Médica, 12(1), 47-53.

8. Curry, L. (1999). Cognitive and learning styles in medical education. Academic Medicine, 74, 409-13.

9. Correa, J. E. (2006). Identificación de los estilos de aprendizaje en los estudiantes de fisiología del ejercicio en la Facultad de Rehabilitación y Desarrollo Humano. Revista de Ciencias de la Salud Bogotá (Colombia), 4(Esp.), 41-53.

10. Soria, M., Guerra, M., Lou, M., Pié, J., Escanero, J. F. (2005). Estilos de aprendizaje de los estudiantes de ciencias de la salud. Educación Médica, 8(3), 145.

11. Ordoñez, F. J., Rosety-Rodriguez, M., Rosety-Plaza, M. Análisis de los estilos de aprendizaje predominantes en los estudiantes de Ciencias de la Salud. Enfermería Global (Servicio de Publicaciones de la Universidad de Murcia); 2003; 3. www.um.es/eglobal/3/03c04.html

12. Canalejas, M., Pérez, M., Martín, L., Pineda, M., Vera, M., Soto, M., Martín Marino, A., Cid, M. (2005). Estilos de aprendizaje en los estudiantes de enfermería. Educación Medica, 8(2), 33-40. 
13. Díaz-Véliz, G., Mora, S., Lafuente J. V., Gargiulo, P., Bianchi, R., Terán, C., Gorena, D., Arce, J., Escanero, J. F. (2009). Estilos de aprendizaje de estudiantes de medicina en universidades latinoamericanas y españolas: relación con los contextos geográficos y curriculares. Educación Médica, 12(X), en prensa. 


\section{CANFIELD}

El CLSI (Canfield's Learning Styles Inventory) sirve para determinar las preferencias de estudio de los alumnos y se centra más en las dimensiones adicionales y afectivas que en las cognoscitivas. Mide las preferencias de aprendizaje definidas por un modelo para describir los estilos de aprendizaje que se centran en los factores motivacionales y ambientales presentes en situaciones formales de enseñanza (1).

Se incluye aquí la definición de estilo de aprendizaje de Canfield para mejor comprender la finalidad de esta herramienta: «El término 'Estilo de Aprendizaje' refiere al componente afectivo de la experiencia educacional, que motiva al estudiante a elegir, atender, y desarrollar bien un curso» (2).

Los autores no ofrecen ninguna explicación sobre la historia del instrumento. Albert A. Canfield y Judith S. Canfied desarrollaron además el Instructional Styles Inventory (ISI) que es muy parecido al CLSI (1).

\section{Material y métodos}

\section{a) Muestra de estudio}

Se desarrolló un estudio transversal en el que se incluyeron 166 estudiantes de la Facultad de Medicina de la Universidad de Zaragoza en España $(n=166)$ pertenecientes a primero (62), tercero (55) y quinto (49) cursos. Los estudiantes que participaron en el estudio fueron los que un día aleatoriamente elegido estaban en clase.

\section{b) Herramienta}

1) Categorías y dominios de aprendizaje

El CLSI es una herramienta o instrumento de autoinforme que se basa en un ordenamiento por hilera de elecciones para cada uno de los 30 ítems o preguntas que, a su vez, se agrupan en 4 categorías, 
cada una de ellas, con excepción de la última, incluye diferentes dominios (escalas) del aprendizaje: la primera se refiere a las Condiciones para el aprendizaje o para aprender, la segundo trata de las Áreas de interés, la tercera es el Modo de aprender y la última se refiere a la Actuación (expectativa). Además, permite determinar la Expectativa global y la Tipología de Aprendedor. El estudiante responde ordenando por preferencia las 4 respuestas de cada pregunta (1=muy preferida, $2=$ preferida, $3=$ no tan preferida, $4=$ menos preferida).

Los dominios que integran las categorías se exponen y definen en la siguiente tabla abierta:

TABLA 18.

Categorías y dominios de cada una de ellas en el Canfield

I. Condiciones para aprender (8 dominios):

1. Compañeros: Disfruta con el trabajo en equipo y mantienen buenas relaciones entre ellos.

2. Organización: Desea que el trabajo del curso este claramente organizado y los deberes sean relevantes.

3. Objetivos (establecimiento de): Quiere tener objetivos y procedimientos propios, pudiendo utilizar el feedback para modificarlos.

4. Competición: Necesita comparar los logros propios con los de los otros.

5. Profesor: Disfruta una relación de amistad mutua y comprensión con el profesor.

6. Detalle: Desea información específica acerca de los logros a conseguir, normas y requerimientos.

7. Independencia: Le gusta trabajar independientemente y determinar su propio plan de estudios.

8. Autoridad: Le gusta una clase disciplinada y profesores competentes.

II. Áreas de interés (4 dominios):

1. Numérica: Prefiere trabajar con números y lógica.

2. Cualitativa: Le gusta trabajar con palabras o lenguaje.

3. Inanimado: Le gusta trabajar con cosas, como en la construcción, reparación, diseño, trabajo con maquinaria.

4. Gente: Le gusta trabajar con gente, entrevistando, asesorando, vendiendo, o ayudando.

III. Modo de aprender (4 dominios):

1. Escuchando: prefiere oír clases, discos o discursos.

2. Lectura: prefiere leer libros, artículos o información bibliográfica.

3. Icónico: Le gusta interpretar diagramas, películas, fotografías, gráficos.

4. Experiencia directa: Aprende haciendo o actuando como en un taller, trabajo de campo o clases de laboratorio. 


\section{Expectación para la evaluación del curso:}

1. Expectación-A: Extraordinaria.

2. Expectación-B: Por encima de la media.

3. Expectación-C: Media.

4. Expectación-D: Por debajo de la media.

5. Expectación total: Promediada.

\section{2) Tipología de aprendedor}

Para llegar a la tipología de aprendedor es preciso combinar varios dominios de las tres primeras categorías de la tabla anterior. Se trata de las siguientes: Organización, Cualitativa, Lectura (Leyendo), Experiencia directa, Inanimado, Icónico, Compañeros, Profesor (Instructor), Objetivo e Independencia.

Con ellas se construye los campos X e Y:

Campo X = Organización + Cualitativa + Lectura - Experiencia directa - Inanimado - Icónico.

Campo Y = Compañeros + Instructor - Objetivo - Independencia .

Traduciendo lo anterior (1) podría decirse que el estilo individual de aprendizaje se deriva de los siguientes factores:

- Condiciones académicas (relaciones con el profesor y compañeros),

- Condiciones estructurales (organización y detalle),

- Condiciones de rendimiento (fijación de objetivos, competición),

- Contenido (números, palabras, etc.),

- Modo de aprendizaje preferido (audición, lectura, icónico, experiencia directa) y

- Experiencia del nivel de desempeño (superior a satisfactorio).

Según las puntuaciones obtenidas en los campos X e Y se obtiene una u otra tipología de acuerdo con la siguiente tabla, donde se indican los nueve tipos de aprendedores (3). 
TABLA 19.

Tipología de aprendedor

\begin{tabular}{lccc}
\hline & X menos de -15 & X de -15 a 15 & X mayor de 15 \\
\hline $\begin{array}{l}\text { Y mayor } \\
\text { de } 10\end{array}$ & $\begin{array}{c}\text { SA } \\
\text { (Social/Aplicado) }\end{array}$ & $\begin{array}{c}\text { S } \\
\text { Social }\end{array}$ & $\begin{array}{c}\text { S/C } \\
\text { Social/Conceptual }\end{array}$ \\
$\begin{array}{l}\text { Y desde } \\
-10 \text { a } 10\end{array}$ & A & N & C \\
Y menos & (Aplicado) & Neutral (Preferencia) & Conceptual \\
$\begin{array}{l}\text { De -10 } \\
\text { Conceptual) }\end{array}$ & (Independiente/Aplicado) & Independiente & IC \\
\hline
\end{tabular}

Como puede observarse en la tabla precedente existen cuatro tipos puros: Social, Independiente, Aplicado y Conceptual; otros cuatro mixtos: Social/Aplicado, Social/Conceptual, Independiente /Aplicado e Independiente/Conceptual y uno Neutral (de Preferencia Neutra).

Los estudiantes tienden a estar más cómodos e implicados en el aprendizaje cuando las técnicas instruccionales se alinean con las suyas o con las de un grupo cercano.

A continuación, a título informativo, se exponen las características de los cuatro tipos puros y del de preferencia neutral (4).

Social: prefiere muchas oportunidades para interactuar con los compañeros y profesores y el trabajo en grupo. No tiene grandes preferencias para las aproximaciones aplicadas o conceptuales. La instrucción que implica discusión en pequeños grupos y solución de problemas, proyectos cooperativos y debates es la más apropiada.

Independiente: prefiere trabajar solo para conseguir objetivos individuales. No tiene grandes preferencias para las aproximaciones aplicadas o conceptuales. Las técnicas instruccionales como análisis de casos prácticos o programas auto-seleccionados o programados por el mismo -aprender a su propio ritmo-, lecturas, tareas por escrito... crearán lo que más se acerca a sus preferencias.

Aplicado: prefiere trabajar en actividades directamente relacionadas con la experiencia del mundo real. No tiene grandes preferencias para las aproximaciones sociales o independientes. Las 
actividades preferidas son las prácticas, visitas médicas, simulaciones, trabajos de laboratorio, resolver problemas, desempeñar roles...

Conceptual: prefiere enfoques verbales altamente organizados. No tiene grandes preferencias para las aproximaciones social o independiente. Las actividades preferidas implican la clase expositiva, lecturas, escritos, estudio de casos...

Preferencia Neutral: no tienen preferencias claras. Pueden responder a cualquier método pero, a veces, pueden encontrar difícil implicarse en una experiencia concreta de aprendizaje.

No se incluyen las características de los tipos mixtos, aunque podrían deducirse a partir de los puros, debido a la muy escasa representatividad entre los alumnos.

\section{Resultados}

a) Categorías y dominios de aprendizaje

En la siguiente tabla se indican las puntuaciones medias obtenidas en los diferentes dominios o escalas de cada categoría.

1. En la categoría «Condiciones para el Aprendizaje», los estudiantes de Zaragoza prefieren el Detalle $(\mu=9,04)$, mientras que la escala menos preferida es la Competición $(\mu=17,26)$. A los estudiantes de Zaragoza no les gusta comparar sus auto-complejos con los de los demás.

Los análisis por cursos revelan que la preferencia por el «Detalle» en los alumnos de quinto curso es mayor que la de los de tercero y primero. Es decir, que a lo largo de su formación los alumnos se hacen más detallistas. Asimismo, los alumnos de quinto son más organizados que los de primero y menos competitivos que los de tercer y primer curso.

2. En la categoría «Área de interés», se advierte claramente que los estudiantes de Zaragoza (en conjunto) manifiestan un interés alto por la Gente $(\mu=12,07)$, preferencia que se incrementa al llegar a quinto curso; mientras que las áreas de interés menos preferidas 
TABLA 20.

Estudiantes de Medicina según puntuaciones medias de preferencia en las escalas de categorías del Cuestionario CLSI

\begin{tabular}{|c|c|c|c|c|}
\hline $\begin{array}{l}\text { Categorías y Escalas } \\
(\mu, d e)^{\star}\end{array}$ & $\begin{array}{c}\text { Zaragoza } \\
(n=166)\end{array}$ & $\begin{array}{c}\text { Primer } \\
\text { Curso (62) }\end{array}$ & $\begin{array}{c}\text { Tercer } \\
\text { Curso (55) }\end{array}$ & $\begin{array}{c}\text { Quinto } \\
\text { Curso (55) }\end{array}$ \\
\hline \multicolumn{5}{|l|}{ Condiciones de aprendizaje } \\
\hline Compañeros & $15.17(3.11)$ & $14.68(3.33)$ & $15.11(2.48)$ & $15.88(3.38)$ \\
\hline Organización & $11.81(2.73)$ & $12.81(2.54)$ & $11.24(2.46)$ & $11.18(2.92)$ \\
\hline Objetivo & $15.64(3.13)$ & $15.87(3.69)$ & $16.00(2.65)$ & $14.94(2.78)$ \\
\hline Competición & $17.26(2.81)$ & $16.34(2.90)$ & $17.64(2.56)$ & $18.00(2.69)$ \\
\hline Instructor & $11.83(4.01)$ & $11.39(2.75)$ & $11.27(2.67)$ & $13.02(5.97)$ \\
\hline Detalle & $9.04(2.63)$ & $9.32(2.70)$ & $9.36(2.34)$ & $8.33(2.76)$ \\
\hline Independencia & $15.10(2.95)$ & $15.74(3.12)$ & $14.78(2.95)$ & $14.65(2.63)$ \\
\hline Autoridad & $14.22(2.82)$ & $13.56(2.67)$ & $14.58(2.76)$ & $14.63(2.98)$ \\
\hline \multicolumn{5}{|l|}{ Área de Interés } \\
\hline Numérico & $16.61(3.43)$ & $16.02(3.30)$ & $16.33(3.44)$ & $17.69(3.38)$ \\
\hline Cualitativo & $15.01(3,78)$ & $15.56(3.87)$ & $15.45(3.39)$ & $13.79(3.88)$ \\
\hline Inanimado & $16.25(3,63)$ & $16.23(3.88)$ & $16.44(3.28)$ & $16.06(3.76)$ \\
\hline Gente & $12.07(3.20)$ & $12.03(3.28)$ & $11.78(3.05)$ & $12.45(3.27)$ \\
\hline \multicolumn{5}{|l|}{ Modo de Aprendizaje } \\
\hline Escuchando & $14.28(3.79)$ & $15.15(3.45)$ & $14.55(3.23)$ & $12.88(4.53)$ \\
\hline Leyendo & $18.77(4.36)$ & $18.43(4.26)$ & $20.44(3.95)$ & $17.33(4.39)$ \\
\hline Icónico & $13.92(3.97)$ & $14.26(4.06)$ & $12.56(3.42)$ & $15.02(4.08)$ \\
\hline Experiencia Directa & $12.97(4.31)$ & $12.02(4.29)$ & $12.45(3.56)$ & $14.78(4.62)$ \\
\hline Nivel Superior «A» & $15.54(4.37)$ & $15.11(3.96)$ & $16.42(4.52)$ & $15.08(4.62)$ \\
\hline Promedio/Bueno «B» & $9.68(2.78)$ & $9.48(2.36)$ & $9.76(3.45)$ & $9.84(2.46)$ \\
\hline Promedio/Satisfactorio "C» & $13.27(3.16)$ & $13.34(2.86)$ & $13.05(3.23)$ & $13.43(3.47)$ \\
\hline Nivel Insatisfactorio «D» & $21.33(3.69)$ & $21.90(2.84)$ & $20.58(4.76)$ & $21.45(3.19)$ \\
\hline Expectativa Global & $34.96(17.36)$ & $32.92(15.07)$ & $38.43(19.37)$ & $33.63(17.43)$ \\
\hline
\end{tabular}

${ }^{*} \boldsymbol{\mu}=$ media aritmética; $\boldsymbol{d e}=$ desviación estándar

son la Numérica $(\mu=16,61)$, tienen poco interés por trabajar con el manejo de números, y la Inanimada $(\mu=16,25)$.

Comparando promedios por curso se advierte que al llegar a quinto curso los alumnos prefieren mucho menos los números que en los años inferiores. En cambio, el interés por lo «cualitativo» se incrementa al llegar a quinto. 
3. En la categoría «Modo de aprendizaje», referida a la modalidad sensorial y cognitiva básica mediante la cual se puede adquirir información nueva, la escala más preferida por los estudiantes de manera general es la Experiencia Directa $(\mu=12,97)$, indicando claramente la preferencia por actividades manuales como trabajos prácticos o de laboratorio. La escala menos preferida es la Lectura $(\mu=18,77)$.

Analizando por curso, se observa que los alumnos de primer curso prefieren más aprender mediante la experiencia directa, pero al llegar a quinto curso ésta preferencia de aprendizaje llegar a ser menor, incrementándose la preferencia de aprender «escuchando». En las otras dos preferencias de aprendizaje (leyendo e icónico) los promedios por curso no varían de manera significativa.

4. En la categoría «Expectativa del curso actual», referida al rendimiento que los estudiantes esperan alcanzar en el curso actual, la escala más preferida por los estudiantes de los diferentes cursos es la B (Promedio/bueno), con cierta mayor expectativa en los alumnos de primer curso y la escala menos preferida, la D.

5. La «Expectativa Global» de todos los estudiantes corresponde a la B $(34,96)$; pero comparando por cursos, los alumnos de primer curso son los que tiene mayor expectativa de pasar el curso de manera satisfactoria, los de tercero tienen menor expectativa y en los de quinto la expectativa mejora.

En general, puede concluirse señalando que: los estudiantes de Zaragoza son detallistas, independientes, bastante organizados, no competitivos, muy interesados en trabajar con la gente y poco con los números, con la experiencia directa como modo de aprendizaje preferido y tienen buenas expectativas para pasar el curso en el que se encuentran.

\section{b) Tipología de Aprendedor}

En la siguiente tabla se recogen los resultados obtenidos de la tipología de aprendedor a la que pertenecen el conjunto de alumnos estudiados. 
TABLA 21.

Distribución de los estudiantes de Medicina según Tipología de Aprendedor

TIPOLOGÍA DE APRENDEDOR

Frecuencia

Social/Aplicado (1)

Aplicado (2)

Independiente/Aplicado (3)

Social (4)

Neutral (5)

Independiente (6)

Social/Conceptual (7) $19.3 \%$

Conceptual (8)

Independiente/Conceptual (9)

TOTAL

Los tres tipos con mayor representación (superior al $10 \%$ ) entre los estudiantes son: los que responden a la tipología Neutral de preferencias de aprendizaje representan el $55.4 \%$ (92 casos), en segundo lugar los de tipo Independiente que suponen un 19,3\% (32 casos) y, finalmente, los Conceptuales que son el $11.4 \%$ (19 casos). El resto representa muy escasos porcentajes, entre 2 y 4 casos, con excepción del Aplicado que son 9 estudiantes (5.4\%).

Por cursos, llama la atención que mientras los porcentajes de los estudiante de tipología de preferencia neutral y los aplicados se incrementan conforme avanzan en los estudios de la carrera, los independientes disminuyen significativamente en quinto curso con respecto a los dos cursos anteriores y todavía más los conceptuales. 
TABLA 22.

Distribución de los estudiantes

de Medicina por Tipología de Aprendedor y por curso

\begin{tabular}{crrrr}
\hline TIPOLOGÍA DE APRENDEDOR & TODOS & Primero & Tercero & Quinto \\
\hline Social/Aplicado (1) & 2 & 0 & 0 & $4.1 \%$ \\
Aplicado (2) & $1.2 \%$ & $0.0 \%$ & $0.0 \%$ & 2 \\
& 9 & 2 & 1 & 6 \\
Independiente/Aplicado (3) & $5.4 \%$ & $3.2 \%$ & $1.8 \%$ & $12.2 \%$ \\
Social (4) & 3 & 2 & 0 & 1 \\
& $1.8 \%$ & $3.2 \%$ & $0.0 \%$ & $2.0 \%$ \\
Neutral (5) & 3 & 1 & 0 & 2 \\
& $1.8 \%$ & $1.6 \%$ & $0.0 \%$ & $4.1 \%$ \\
Independiente (6) & 92 & 30 & 30 & 32 \\
Social/Conceptual (7) & $55.4 \%$ & $48.4 \%$ & $54.5 \%$ & $65.3 \%$ \\
Conceptual (8) & 32 & 14 & 13 & 5 \\
Independiente/Conceptual (9) & $19.3 \%$ & $22.6 \%$ & $23.6 \%$ & $10.2 \%$ \\
TOTAL & 2 & 2 & 0 & 0 \\
& $1.2 \%$ & $3.2 \%$ & $0.0 \%$ & $0.0 \%$ \\
& 119 & 8 & 10 & 1 \\
& $11.4 \%$ & $12.9 \%$ & $18.2 \%$ & $2.0 \%$ \\
& $2.4 \%$ & $4.8 \%$ & $1.8 \%$ & $0.0 \%$ \\
& 166 & 62 & 55 & 49 \\
& $100.0 \%$ & $100.0 \%$ & $100.0 \%$ & $100.0 \%$ \\
\hline
\end{tabular}

\section{Discusión}

Aunque el test se ha venido utilizando principalmente para preparar y desarrollar materiales de instrucción tanto para alumnos individuales como para todo el curso, a nivel universitario Canfield (2) le da un gran valor a la hipótesis del emparejamiento de estilos (5) ya que estima que los estudiantes aprenderán mejor si los métodos y preferencias del profesor son parecidos a los de los estudiantes. Independientemente de la adscripción a una u otra hipótesis (emparejamiento/desemparejamiento) (6), el conocimiento del alumno sirve también para una mejor realización de otras tareas como la tutoría, por ejemplo (7).

No obstante, lo importante de este estudio se centra dos hechos: uno, la descripción de las preferencias de estudio (categorías y dominios del aprendizaje), donde se corroboran una serie de cualidades que habían sido detectadas en otros trabajos (8); así, el interés por 
la gente fue puesto de manifiesto por los alumnos de Medicina cuando se quisieron conocer las motivaciones por las que habían elegido esta carrera, del mismo modo que el interés por la acción, por ejemplo, que aplicado a esta herramienta tiene su correlación con la experiencia directa como modo de aprendizaje preferido; y dos, porque los datos obtenidos, relativos a la tipología, completan los aportados con el CHAEA.

Los resultados obtenidos en las diferentes categorías nos llevan a presentar a los estudiantes de Zaragoza como detallistas, independientes, bastante organizados, no competitivos, muy interesados en trabajar con la gente y poco con los números, con la experiencia directa como modo de aprendizaje preferido y con buenas expectativas para pasar el curso en el que se encuentran. Este último dato no podría ser de otra manera ya que los cortes en la nota de entrada en las Facultades de Medicina superan con mucho en la mayoría de los casos el 8. Si al anterior perfil se añade el hecho de que son mayoritariamente reflexivos (ponderados, concienzudos, receptivos, receptivos, analíticos y exhaustivos) (9) y teóricos (metódicos, lógicos, objetivos, críticos, estructurados) (9), de acuerdo con los datos proporcionados por el CHAEA, el perfil de los estudiantes está perfectamente definido. De manera general, el perfil resulta ejemplar y ha de resultar altamente estimulante para el profesorado.

No obstante, resulta difícil sustraerse en la discusión a no remarcar la poca preferencia manifestada en los modos de aprendizaje por la lectura, lo que sin duda puede manifestar o significar un fuerte rechazo a la enseñanza memorística que se realiza, y entre las condiciones de aprendizaje la poca adhesión a la competitividad, probablemente otra manifestación del rechazo de la experiencia vivida hasta hace muy poco tiempo, donde después de acabar el grado y para poder hacer la especialidad debían aprobar un examen (examen MIR) en donde la competitividad llegaba a unos niveles extremos (número elevado de licenciados por plaza). Este hecho se traducía durante la carrera de Medicina en que los alumnos no se prestasen el material docente, entre otras características, con una clara deformación sobre una serie de cualidades que hoy se reclaman: aprendizaje cooperativo/colaborativo, trabajo en grupo, solución de problemas, etc. 
Por otra parte, la utilización de esta herramienta ha permitido catalogar a los estudiantes de Medicina con respecto a los tipos de aprendedores de esta escala resultando ser mayoritariamente de preferencia neutra lo que viene a significar que pueden adaptarse y responder a cualquier método de enseñanza. Para otros autores (2) en otros medios los tres tipos más prevalentes serían: aplicados, independientes/aplicados e independientes. En 212 estudiantes de empresariales Stitt-Gohdes $(10,11)$ reportó que la tipología social, social/aplicada e independiente/conceptual eran las más representativas. En este trabajo han sido los tipos neutral, independiente y conceptual los que cuentan con mayor número de estudiantes.

Además de la utilización de esta herramienta para preparar y desarrollar materiales de instrucción tanto para alumnos individuales como para todo el curso, como se ha indicado al inicio de la Discusión, el conocimiento del tipo o estilo de aprendizaje de nuestros alumnos, aunque no compartiéramos la hipótesis del emparejamiento de estilos alumno/profesor ha de servir al profesor para ayudarle en otras muchas tareas (metacognición, tutorías, etc.) y hacer de su función una tarea más cercana con respecto al estudiante y efectiva con relación al aprendizaje.

\section{Bibliografía}

1. Salas, R. E. (2008). Estilos de aprendizaje a la luz de la Neurociencia. Colección Aula Abierta. Colombia, Cooperativa Editorial Magisterio.

http://books.google.com/books

2. Canfield, A. A. (1992). Canfield learning styles inventory (LSI) manual. Los Angeles: Western Psychological Services.

3. Eide, B. J., Geiger, M. A., Schwartz, B. N. The Canfield Learning Styles Inventory: An Assessment of its Usefulness in Accounting Education Research. http://aaahq.org/AM2001/sessions/ab064.pdf

4. Huba, G. J., Gruber, C. P. (1987). Canfield's Learning Styles Inventory (CLSI).

http://portal.wpspublish.com/pdf/lsi.pdf 
5. Escanero, J. F., Mora, S., Arce, J., Bianchi, A. R., Díaz Veliz, G., Gargiulo, P., Gorena, D., Lafuente, J. V., Landa, A. I., Terán, C. (2008). Estilos de aprendizaje (Facultades de Medicina). Zaragoza, Prensas Universitarias de Zaragoza.

6. Coffield, F., Moseley, D., Hall, E., Ecclestone, K. (1998). Should we be using learning styles?. What Research. Learning \& Skills Research Centre, 176, 62-6.

7. Escanero, J. F., González-Haro, C., Ezquerra, L., Borque, L. (2009). Diseño e implementación de una práctica de metacognición en la asignatura de Fisiología Humana (Facultad de Medicina). Educación Médica, 12(1), 47-53.

8. Soria, M., Guerra, M., Escanero, J. F. (2006). La decisión de estudiar Medicina: características. Zaragoza, Prensas Universitarias de Zaragoza. Informe, 2, 52 págs.

9. Gil, P., Contreras, O. R., Pastor, J. C., Gómez Barreto, I., González Villora, S., García López, L. M., Moya, M. del V., López Corredor, A. (2007). Estilos de aprendizaje de los estudiantes de magisterio: especial consideración de los alumnos de Educación Física. Revista de currículum y Formación de Profesorado. http://redalyc.uaemex.mx/src/inicio/ArtPdfRed.jsp?iCve=56711209

10. Stitt-Gohdes, W. L. (2001). Business education students' preferred learning styles. Journal of Career and Technical Education, 18(1), 32-45.

scholar.lib.vt.edu/ejournals/JCTE/v18n1/stitt.html

11. Stitt-Gohdes, W, L. (2001). Business Education Students' Preferred Learning Styles and Their Teachers' Preferred Instructional Styles: Do They Match?. Delta Pi Epsilon Journal, 43(3), 137-51.

www.eric.ed.gov/ERICWebPortal/recordDetail?accno= EJ638597 


\section{Capítulo III}

\section{RECOMENDACIONES}

En este capítulo se presentan una serie de recomendaciones con objeto de mejorar el currículum que se va a implantar en este nuevo curso. Las primeras parten del análisis de la realidad actual de la Facultad de Medicina y las siguientes se han extraído de los resultados que se han obtenido con las diferentes herramientas utilizadas para conocer a los estudiantes (su opinión sobre el contexto, su enfoque en el aprendizaje y su estilo de aprendizaje) y se han elaborado, en consecuencia, desde la visión del otro personaje, el que va a ser el centro del nuevo paradigma y de nuestra actividad.

\section{LA REALIDAD ACTUAL}

\section{Profesorado}

1. La Institución debe iniciar con urgencia los debates necesarios entre profesores, dirigidos por personal externo de la Facultad, con el fin de ahondar en el significado de determinados conceptos. Se ha puesto como ejemplo el término competencia y se han indicado una serie de puntos a tratar.

2. Para la implantación de nuevas tecnologías y metodologías se precisa además del debate y formación, el apoyo humano. Los alumnos de último curso con dedicaciones específicas y/o personal de la 
Administración y Servicios especializado o reconvertido, podrían cumplir con esta tarea de soporte, sin cuya existencia la reforma se verá muy seriamente afectada. Se ha vuelto a sugerir, aunque no a debatir, por suficientemente conocidos, los Departamentos de Educación Médica.

\section{Departamentos}

3. La reforma departamental, adecuada a la nueva realidad, es una acción de índole prioritaria para la adecuada implantación de los grados.

\section{Equipos docentes}

4. Las instituciones deben facilitar el adecuado funcionamiento de los equipos docentes, así como su apoyo y reconocimiento. Los equipos docentes deben:

4a. Trabajar para romper con la creencia de que el conocimiento elaborado por el alumno se corresponde con el mismo tipo de conocimiento que el transmitido por el profesor.

4b. Asumir que los resultados del aprendizaje no dependen tanto de lo enseñado como del trabajo de explicitación, elaboración y reflexión que haga el estudiante con ello, en un contexto de aprendizaje determinado y a partir de cierto tipo de experiencias y de cómo es capaz de trabajar, diseñar su trabajo y dirigir su esfuerzo en este sentido.

4c. Conociendo que las capacidades de los estudiantes, por sí mismas, son limitadas, pero se expanden en ciertos contextos de oportunidad, a partir de determinadas experiencias y mediante retos que le lleven a desarrollar un pensamiento reflexivo más o menos profundo, los profesores deben dedicarse a la creación de «ambientes enriquecidos y motivadores», inductores de la reflexión, y a patrocinar oportunidades de aprendizaje de calidad.

$4 \mathrm{~d}$. No debe olvidarse de la parte colectiva/social que representa el aprendizaje debiéndose fomentar el aprendizaje cooperativo/colaborativo a través de los trabajos en grupo. 
4e. Trabajar para exilar de la Facultad de Medicina el paradigma reflexivo de la enseñanza y la utilización del examen para mantener el sistema dominante.

Personal de administración y servicios

5. La reforma es cuestión de todos. La clarificación de funciones nunca está demás y si el personal de administración y servicios es únicamente personal de gestión, llámese así, y búsquense las oportunas soluciones imaginativas para proporcionar el factor humano preciso que las tareas docentes precisen.

\section{Infraestructuras}

6. Deben generarse las infraestructuras o marcos adecuados: son necesarios de partida, como parte del nuevo ambiente y por su función estimuladora o motivante.

\section{AMBIENTES}

\section{Conclusiones del DREEM}

\section{Zaragoza versus Huesca}

1. La percepción ambiental de los estudiantes de Zaragoza proporciona una más elevada puntuación global que la de los estudiantes de Huesca, así como en cada uno de los ambientes analizados. Estos resultados llaman a una reflexión y estudio de la mejora de la coordinación entre ambos centros.

2. Respecto al aprendizaje: Zaragoza debe:

- dejar de centrar la enseñanza en el profesorado,

- dejar de sobreenfatizar en el aprendizaje de hechos concretos,

- conseguir una mejor programación y

- mejorar la autoconfianza de los estudiantes. 
Huesca debe:

— no sólo dejar de estar centrada en el profesor sino, como insisten, centrarse en el alumno,

- dejar de sobreenfatizar sobre hechos concretos,

- no sólo generar la autoconfianza de los estudiantes sino también ayudarle a desarrollar sus competencias,

- mejorar el enfoque de la enseñanza y

- especialmente y con premura corregir la programación.

3. Respecto a la enseñanza/profesorado: Zaragoza y Huesca necesitan con carácter urgente corregir algunos hechos respecto al comportamiento del profesorado en clase, en relación con los alumnos.

4. El ambiente académico tienen una valoración positiva en ambos centros.

5. En la valoración del ambiente de aprendizaje Zaragoza no precisa de mejoras o correcciones. En cambio, en Huesca, los alumnos vuelven a reclamar una adecuada programación, programas y/o cambios para hacer menos decepcionante su paso por la Facultad y deberá vigilarse y corregirse la posible copia en los exámenes.

6. Respecto al ambiente social deben corregirse los siguientes hechos: valoración del sistema de apoyo a los estudiantes que se estresan y a los que se aburren. Los alumnos de Huesca tienen los mismos problemas aunque más exacerbados y, sobre todo, necesitan del establecimiento de programas de actuación para combatir el cansancio que reconocen.

\section{Zaragoza}

7. Comparando los resultados del conjunto de alumnos (primero, tercero y quinto cursos) de Zaragoza podría decirse que las puntuaciones correspondientes a las percepciones del aprendizaje y la enseñanza/profesores (los dos primeros ambientes) pueden y deben mejorarse, mientras que el resto de ambientes: académico, atmósfera de aprendizaje y social presentan una puntuación considerablemente buena. Un hecho especial debe tenerse presente. Se trata del llamativo y significativo descenso en la puntuación de todos los 
ambientes explorados que se consigue cuando los alumnos llegan al quinto curso. Puede que a partir de tercero, todos los cursos de la Facultad de Medicina de Zaragoza sean cursos diana para intentar mejorar los ítems referidos a ambiente.

8. En lo que respecta al aprendizaje, de los resultados más globales obtenidos de los alumnos de primero, tercero y quinto cursos, debe concluirse que mientras que para los alumnos de primero y tercero se constatan y refrendan los resultados y recomendaciones hechas anteriormente (Zaragoza versus Huesca) para los de quinto se recomienda mejorar en todos y cada uno de los ítems de este apartado, con excepción de los objetivos de aprendizaje.

9. Respecto a la enseñanza/profesorado, éstos deben mejorar, como también se insistía más arriba, en especial, su carácter autoritario, el que se molesten en clase y se irriten con los alumnos. En quinto curso se debe mejorar con prioridad la retroalimentación, las molestias en clases, el potenciamiento de la crítica constructiva y la habilidad en relacionarse con los pacientes (¿?).

10. Respecto al ambiente académico, debe trabajarse para que los alumnos de quinto curso cambien la percepción que tienen sobre la consideración de cómo les están formando, así como sobre las dudas que presentan de si lo que estudian es relevante para la Medicina y sobre sus habilidades para resolver problemas. Las acciones implantadas deberían extenderse al curso anterior y continuarse en el siguiente.

11. Respecto a la atmósfera de aprendizaje, los alumnos de quinto reclaman mejoras en la programación de los tiempos, la motivación para el aprendizaje y, especialmente, para la búsqueda de caminos donde descubrir y/o aumentar el placer del estudio de la Medicina, con objeto de superar el estrés que éste le produce.

12. Respecto al ambiente social, como se ha indicado más arriba, es preciso trabajar y hacer más visibles las ayudas existentes para combatir el estrés de los estudiantes, así como trabajar sobre el cansancio manifestado por los alumnos de quinto curso. 


\section{ENFOQUE}

\section{Conclusiones del ASSIST}

1. Favorecer la implantación de las condiciones necesarias para que los aprendedores estratégicos pasen a ser profundos.

2. Implantar prácticas de metacognición para el análisis de estrategias utilizadas por los aprendedores superficiales e incorporar el tratamiento de los aprendedores superficiales en las tutorías.

3. Establecer los cambios metodológicos pertinentes que permitan cambiar las aptitudes y actitudes de los aprendedores con enfoque superficial.

3. Fomentar las actividades que permitan discutir, relacionar e integrar ideas ya que se trata del hábito de estudio menos valorado por los aprendedores profundos.

\section{ESTILOS}

\section{Conclusiones CHAEA}

1. Los estudiantes de Zaragoza pertenecen mayoritariamente a los estilos reflexivo y teórico (CHAEA) y, en terminología de Kolb, al asimilador. Se postula con la influencia que puede tener sobre el estilo el paradigma docente predominante en medicina (clase magistral).

2. Se recomienda buscar alternativas metodológicas para potenciar el desarrollo de los estilos activos y pragmáticos. El estudiante más capacitado será aquel capaz de aprender en cualquier situación, ya que aprovechará mejor las oportunidades de aprendizaje que se le presenten a lo largo de su vida. Esta recomendación parece estar cumplida en el nuevo currículum dado el considerable incremento de actividades con pequeños grupos. 


\section{PREFERENCIAS Y ESTILOS}

\section{Conclusiones CANFIELD}

1. Lo importante de este estudio se centra en la descripción de las preferencias de estudio (categorías y dominios del aprendizaje). Nuestros alumnos de acuerdo con estos resultados son bastante ejemplares, siendo de destacar el interés por la gente.

2. Se debe mejorar, en cuanto al modo de aprendizaje se refiere, el menos preferido que es la lectura, para lo cual deben diseñarse actividades que la estimulen: debates sobre revisiones de calidad de diferentes temas, problemática médica actual, etc.

3. La utilización de problemas o casos, potenciando la búsqueda de información y el trabajo colaborativo o cooperativo donde cada alumno tenga misiones claras de aspectos que aportar sería otra actividad a tener en cuenta.

Los siguientes, dos últimos puntos, no tienen el carácter de recomendación sino de información para conocimiento de nuestros alumnos; la siguiente es la foto que nos proporciona esta herramienta y la última corresponde al tipo de aprendedores predominantes entre los alumnos de la Facultad.

4. En general, el perfil de los estudiantes de Zaragoza podría ser como sigue: son detallistas, independientes, bastante organizados, no competitivos, muy interesados en trabajar con la gente y poco con los números, con la experiencia directa como modo de aprendizaje preferido y con buenas expectativas para pasar el curso en el que se encuentran.

5. Respecto a los estilos de aprendizaje de los alumnos, según esta herramienta, con carácter informativo y con el mismo criterio que en la conclusión primera del CHAEA, son de tipología Neutral, le siguen de lejos los de tipo Independiente y, en tercer lugar, los Conceptuales con mucha menor representatividad. 


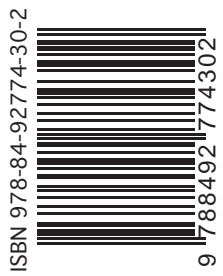

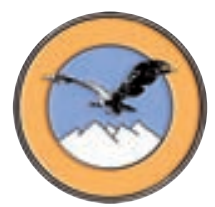

Universidad Andina Simón Bolívar (Sucre, Bolivia)

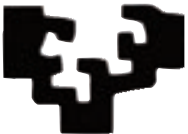

Universidad del País Vasco Euskal Herriko Unibertsitatea

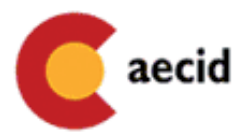

Agencia Española de Cooperación Internacional para el Desarrollo

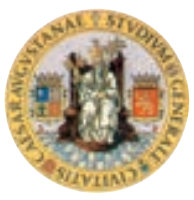

Universidad de Zaragoza

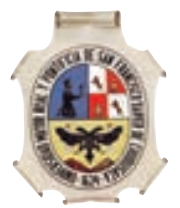

Universidad Mayor, Real y Pontificia de San Francisco Xavier de Chuquisaca (Bolivia)

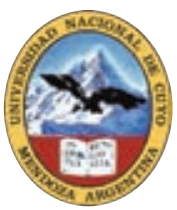

Universidad Nacional de Cuyo (Mendoza, Argentina)

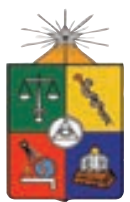

Universidad de Chile (Santiago de Chile) 